\title{
Os vínculos entre a geografia brasileira e a geografia cubana: instituições, redes e círculos de afinidades
}

Adélia Aparecida de Souza Haracenko

Departamento de Geografia. Universidade Estadual de Maringá. Paraná, Brasil.

Recibido: 24 de marzo de 2021. Aceptado: 07 de mayo de 2021.

\begin{abstract}
Resumo
Este artigo apresenta parte dos resultados de uma investigação que teve como objetivo a compreensão das relações e dos vínculos estabelecidos entre a geografia brasileira e cubana. A problemática de investigação partiu do pressuposto que a geografia, desde a segunda metade do século XIX, esteve a serviço dos interesses dos países colonialistas e imperialistas, haja vista que tanto a geografia brasileira quanto a cubana foram influenciadas por teorias europeias. Nesse sentido, procuramos identificar relações de intercâmbio entre ambas, dando ênfase à importância da geografia que se faz entre os geógrafos da América Latina. Os procedimentos metodológicos de coleta das informações e dos dados relevantes se sustentaram nos referenciais bibliográficos e nas entrevistas com geógrafos dos dois países. A história e a fonte oral foram primordiais na busca das informações primárias. Nele abordamos os seguintes assuntos: os períodos em que os vínculos foram estabelecidos, as instituições que participaram do intercâmbio, as redes e os círculos de afinidades que se construíram através dos laços estabelecidos entre os pesquisadores. Tomando o sentido de que integrar é aprender de ambas as partes, é consolidar-se, este trabalho se junta a lista dos que pretendem contribuir para a construção de uma geografia latino-americana compartilhada.
\end{abstract}

PALAVRAS-CHAVE: GEOGRAFIA. BRASIL. CUBA. VÍNCULOS. CÍRCULOS DE AFINIDADES.

\section{The bonds between Brazilian geography and Cuban geography: institutions, networks, and affinity circles}

\begin{abstract}
This article presents part of the results of an investigation that aimed to understand the relationships and bonds established between Brazilian and Cuban geography. The research problem started from the assumption that geography, since the second half of the 19th century, served the interests of colonialist and imperialist countries, given that both Brazilian and Cuban geography were influenced by European theories. In this sense, we seek to identify interchange relations between the two of them, emphasizing the importance of geography between geographers in Latin America. The
\end{abstract}


AdÉLIa APARECIDA dE SOUZA HARACENKo

methodological procedures for collecting relevant information and data were sustained both in bibliographic references and in interviews with geographers from both countries. History and the oral source were essential in the search for primary information. In it we address the following subjects: the periods in which the bonds were established, the institutions that participated in the exchange, the networks and circles of affinities that were built through the ties established between the researchers. Considering that to integrate is to learn from both sides, it is to consolidate, this work joins the list of those who intend to contribute to the construction of a shared Latin American geography.

KEYWORDS: GEOGRAPHY. BRAZIL. CUBA. BONDS. AFFINITY CIRCLES.

PALABRAS CLAVE: GEOGRAFÍA. BRASIL. CUBA. VÍNCULOS. CÍRCULOS DE AFINIDADES.

\section{Introdução}

Este texto tem por finalidade apresentar parte dos resultados obtidos em uma pesquisa desenvolvida durante o nosso estágio de pós-doutoramento, ${ }^{1}$ cujo objetivo foi identificar os vínculos entre a geografia brasileira e a geografia cubana. A problemática que motivou essa pesquisa partiu do pressuposto que a geografia, desde a segunda metade do século XIX, se transformou numa ciência a serviço dos interesses dos países colonialistas e imperialistas europeus (Capel, 2012). Desta maneira, na medida em que o colonialismo foi se desenvolvendo serviu de um veículo de inculcação ideológica na relação dos conquistadores com as populações dos lugares colonizados (Moreira, 2014). Nesse sentido, a geografia brasileira foi marcada e influenciada majoritariamente pelas teorias europeias, francesas e alemãs e, sob elas, o território brasileiro foi sendo construído. Com isso, grande parte dos geógrafos brasileiros -evidentemente há exceções- foi em suas graduações acostumada a olhar e ler o mundo latino pelos olhos e lentes das teorias europeias. Não fugindo a regra dos países latino-americanos, a geografia cubana também sofreu influência das teorias europeias e norte-americanas. Mateo Rodríguez (2015:181) diz que: "Para la geografía cubana el análisis de la geografía soviética tiene un significado fundamental, debido al importante papel desempeñado por esta corriente en su formación y consolidación (...)”. Diante disso é que almejamos identificar as relações de intercâmbio entre a geografia brasileira e cubana.

Os procedimentos metodológicos de coleta das informações e dos dados que sustentaram o arcabouço investigativo se pautaram tanto nos referenciais bibliográficos quanto em entrevistas. Entre as referências, Berdoulay (2017), ao discutir a formação dos círculos de afinidade, nos permitiu compreender esse fator como um constructo teórico, resultante das relações estabelecidas entre os geógrafos dos dois países. Já para as entrevistas, fizemos uso da história oral, porém, cabe ressaltar, que há muitos autores que têm se dedicado a essa temática, procurando dar sustentação ao termo. Todavia, de Queiroz (1991:5) salienta que “(...) 'história oral' é um termo amplo que recobre uma quantidade de relatos a respeito dos fatos não registrados por outro tipo de documentação, cuja documentação se quer completar". Como é colhida através de entrevistas

1 Trata-se de uma investigação desenvolvida ao longo de nosso estágio de pós-doutoramento realizada durante o período de março de 2018 a março de 2019 no Instituto de Geografia "Romualdo Ardissone", da Faculdade de Filosofia e Letras da Universidade de Buenos Aires (UBA), intitulada: Os vínculos entre a geografia brasileira e a geografia cubana: redes, instituições e textos. Este projeto esteve vinculado ao grupo de pesquisa da professora Perla Zusman e ao seu projeto investigativo: Geografías discursivas y visuales en los procesos de (re)configuración territorial. De la formación estatal a las reivindicaciones identitarias de inicios del siglo XXI. 
das mais variadas formas, ela pode registrar a experiência de um único indivíduo, como de um grupo de pessoas inserido numa coletividade. A realização das entrevistas com geógrafos e geógrafas do Brasil e Cuba fez com que valorássemos a história oral como uma importante fonte, simbolicamente, uma nascente de onde brotaram informações preciosas, como podemos conferir nos excertos de entrevistas ao longo deste texto.

As perguntas que orientaram a investigação foram: como se estabeleceram os vínculos entre a geografia brasileira e cubana? Quais instituições e pessoas propiciaram o desenvolvimento dessas relações? Seria possível identificar períodos em que as relações foram mais intensas? Quais práticas foram desenvolvidas para fortalecê-las? Houve a construção de redes institucionais?

Desta maneira, obtivemos nos discursos geográficos dos entrevistados um instrumento de construção da história do pensamento geográfico e, ousamos dizer, construção do pensamento geográfico latino-americano. Dito isto, no decorrer desse trabalho o leitor será levado a transitar por elementos da geografia brasileira e da geografia cubana por meio das falas dos depoentes. Assim, tomamos emprestado de Moreira (2011:10), de seu livro Pensar e Ser em Geografia, o excerto que diz que o leitor “(...) é convidado a circular nas veredas desse pensamento em sua busca incessante de ajudar os homens a clarificar o mundo como mundo do homem".

Dito isto, o artigo está apresentado em cinco partes. Na primeira, analisamos os contatos dos geógrafos cubanos com os brasileiros, por meio da participação dos primeiros no XVIII Congresso da União Geográfica Internacional (UGI), que ocorreu na cidade do Rio de Janeiro no ano de 1956. Na segunda, tratamos de mostrar o início dos vínculos ocorridos a partir do final dos anos de 1980. Na terceira parte, procuramos revelar a intensificação dos intercâmbios a partir dos anos de 1990, dando ênfase nesse contexto à influência da obra $\mathrm{e}$ do pensamento de Milton Santos na geografia de Cuba. Na quarta, trazemos a importância dos projetos de cooperação entre instituições do Brasil e de Cuba que fomentaram as pesquisas entre os geógrafos de ambos os países. Na última parte, abordamos as instituições brasileiras por meio das quais seus pesquisadores fortaleceram vínculos com Cuba. Damos ênfase aos geógrafos das três universidades aqui estudadas que foram: Universidade Federal do Ceará (UFC), Universidade Estadual Paulista (UNESP), Campus de Presidente Prudente, e Universidade de Havana (UH). Neste último item também abordamos as redes e os círculos de afinidades construídos através do desenvolvimento dos trabalhos científicos. Finalmente, incorporamos algumas considerações a título de conclusão do artigo.

\section{A participação dos geógrafos cubanos no XVIII Congresso da União Geográfica Internacional em 1956}

O desenvolvimento da geografia no Brasil como ciência chega à década de 1950 bastante avançado, tanto no meio das instituições universitárias quanto pela atuação das demais instituições que da geografia faziam uso para a construção do território nacional. Os anos específicos da década de 1950 são marcados politicamente pelas presidências de duas das maiores figuras políticas brasileiras do século XX, Getúlio Dornelles Vargas e Juscelino Kubistchek de Oliveira -normalmente denominado nos livros pelas siglas iniciais do seu nome, como presidente JK-. Eles vão fazer profundas transformações políticas e sociais no território brasileiro. 
Getúlio Vargas, que anteriormente governou o país de 1930 a 1945, período denominado de Era Vargas -no qual foi eleito pelo voto indireto-, retornou à presidência da república em 1950 -desta vez eleito pelo voto popular-, assumindo o seu mandato em 31 de janeiro de 1951. No início dessa década o seu governo promoveu várias medidas destinadas a incentivar o desenvolvimento econômico, dando ênfase na industrialização do país. Em meio às crises econômicas e políticas, em 24 de agosto de 1954 Getúlio Vargas se suicidou. Isto levou o seu vice-presidente, João Fernandes Campos Café Filho a chamar eleições presidenciais em outubro de 1955. Em 3 de outubro desse mesmo ano, as urnas deram vitória à Juscelino Kubitschek. O período $J K$ que vai de 1956 a 1961, também denominado na história brasileira como Anos Dourados, foi um período marcante apesar das crises. O país que pretendia ser moderno e industrializado vai deixar suas impressões em diversas áreas, por exemplo, na música desponta a Bossa Nova e no futebol é vitorioso na Copa do Mundo de 1958. JK lançou no Brasil o Plano de Metas, no qual pretendia desenvolver setores estratégicos ligados à indústria de base, energia, transportes, alimentação e educação. Sobre o Plano de Metas de JK, de Campos (2011:154) afirma: "Com seu Programa de Metas, desejoso de fazer $5 O$ anos em 5, o presidente bossa-nova adotou uma política de expansão da economia brasileira, integrando-o ao capitalismo estadunidense". Com essa integração, muitas foram as possibilidades do estabelecimento de indústrias que requisitavam o amplo conhecimento do território.

Na construção do desenvolvimento brasileiro, naquele período dos idos de 1950 em que a palavra modernização tinha um significado prioritário, a geografia foi um ramo importante do conhecimento que contribuiu nessa tarefa. Nessa década a primeira geração de geógrafos e geógrafas brasileiros -que foi treinada por professores estrangeiros, com maior ênfase aos franceses- começou a fazer pesquisa sob sua própria responsabilidade em diferentes universidades. A Associação dos Geógrafos Brasileiros (AGB) se fortaleceu e teve uma expansão em nível nacional com assembleias e encontros que ocorreram em diversas cidades do país. No Instituto Brasileiro de Geografia e Estatística (IBGE), os pesquisadores avançaram em suas tarefas de conhecimento do território nacional, progredindo com isso, também nesse órgão, a geodésia e a cartografia. Em 1952, ocorreu o Congresso Internacional de Geografia em Washington onde os geógrafos brasileiros se fizeram presentes em grande número. Essa forte presença possibilitou sediar o próximo congresso da União Geográfica Internacional no Brasil, que ocorreria no ano de 1956 (Valverde, 1984; Scarim, 2000).

É, portanto, nesse contexto que entre os dias 9 e 18 de agosto de 1956 na Escola Naval do Rio de Janeiro, localizada na Ilha de Villegagnon na Baía de Guanabara no estado do Rio de Janeiro, que aconteceu o XVIII Congresso da Union Géographique Internationale (UGI). Tratou-se de um evento que recebeu geógrafos e geógrafas de vários países do mundo. Conforme dados extraídos dos Comptes Rendus du XVIIIème Congrès International de Géographie. Tome Premier. Actes du Congrès (UGI, 1956), dos 59 países cujos geógrafos e geógrafas estiveram inscritos no congresso, 53 estiveram efetivamente presentes, dentre eles se encontravam as mais renomadas figuras do mundo geográfico daquele período. Assim, o evento contou com 1220 inscrições, entre membros individuais e institucionais, e com cerca de 270 comunicações.

Tomando a via das relações construídas entre os geógrafos e geógrafas brasileiros -naquele momento ainda muito jovens-, tiveram ali a oportunidade de estabelecer 
relações com geógrafos e geógrafas de outras nacionalidades. Em entrevista a Evangelista (2014), Milton Santos assim se refere: "Foi naquele congresso que se abriram as portas, para nós geógrafos brasileiros, para o mundo, com a vinda de grandes nomes que vieram prestigiar esse evento e que foi bastante divulgado na imprensa" (Santos, 1991 citado por Evangelista, 2014:214).

Entre os geógrafos e geógrafas do mundo que participaram do Congresso, estavam os cubanos. Conforme os Comptes Rendus du XVIIIème Congrès International de Géographie. Tome Premier. Actes du Congrès (UGI, 1956:7), na delegação nacional de Cuba consta o nome do geógrafo Salvador Massip. Na página 18 do referido documento há os membros individuais da delegação completa, composta por cinco pessoas: Pedro Cañas Abril, Salvador Valdés Massip, Sarah E. Ysalgué de Massip, Antonio Núñez Jiménez e José Manuel Ruiz Miyar. Os membros institucionais de Cuba, apontados na página 25, foram: Sociedad Geográfica de Cuba, Universidad Central Marta Abreu de Las Villas e Universidad de La Habana. Essas instituições -destacadas nas páginas 37 e 38- estavam representadas pelos seguintes geógrafos:

» Sociedad Geográfica de Cuba: Salvador Massip e Sarah E. Ysalgué de Massip

» Universidad de La Habana: Salvador Massip e Sarah E. Ysalgué de Massip

» Universidad Central Marta Abreu de Las Villas: José Manuel Ruiz Miyar

Cabe ressaltar que o documento mostra que dentre as nove excursões do evento, que ocorreram por diversas regiões do país, os geógrafos cubanos Salvador Massip, Sarah E. Ysalgué de Massip e José Manuel Ruiz Miyar escolheram a destinada à Amazônia, que teve uma duração de 24 de agosto a 13 de setembro com um valor de US\$175,00. Igualmente, fica o destaque que nos Comptes Rendus du XVIIIème Congrès International de Géographie. Tome Quatrième. Travaux des Sections (UGI, 1956), encontramos dois trabalhos apresentados nesse evento: um na Seção II de Geomorfologia, intitulado Morphology of the so-called submarine platform to the southwest of Cuba de Sarah E. Ysalgué de Massip, e outro na Seção XIII de Geografia Regional, que foi o trabalho de Salvador Massip intitulado Paisajes Geográficos de Cuba. Estas figuras da geografia cubana foram fundamentais para o enriquecimento da ciência geográfica naquele país, e seus trabalhos garantiram a continuidade do desenvolvimento da geografia, tanto no processo investigativo quanto na docência.

Salientamos que não encontramos documentos que atestem que logo após esse encontro, e nos anos seguintes a ele, chegando até a década de 1980, houve algum tipo de relação entre os geógrafos brasileiros e cubanos. Parece-nos, e ousamos dizer, que o olhar dos geógrafos brasileiros estava direcionado para a França já que a delegação francesa naquele evento era uma das mais brilhantes, como dito na fala de Orlando Valverde (1989), citado por da Silva (2012:73). De fato, conforme pontua da Silva (2012), a partir deste evento, revigora-se a influência dos franceses na geografia brasileira. Conforme ainda destaca o autor, este congresso passa a intensificar o contato com uma literatura geográfica específica, sobretudo, de textos básicos da geografia francesa, que muito contribuíram nos anos subsequentes para o preenchimento de certo vazio teórico-metodológico que se dedicava às novas temáticas decorrentes também de uma nova realidade brasileira (da Silva, 2012). 
Nesse sentido, a consideração que chegamos ao analisar a participação dos geógrafos cubanos nesse Congresso de 1956 evidencia dois fatos importantes. O primeiro é saber que este encontro permitiu não necessariamente a criação de vínculos, mas os primeiros contatos entre os geógrafos cubanos e brasileiros. O segundo é o início de um conhecimento, por meio dos textos escritos e apresentados no evento, tanto de Sarah Ysalgué quanto de Salvador Massip, de como a geografia estava se desenvolvendo em Cuba nos idos de 1956. Desta maneira, este evento constitui um marco fundamental para a compreensão desse percurso de contatos que vai desencadear nos vínculos entre os geógrafos e geógrafas dos dois países nas décadas posteriores.

\section{Os anos de 1980: a geografia crítica e o início dos vínculos com a geografia cubana}

As entrevistas mostraram que esses vínculos começaram a surgir somente a partir do final da década de 1980. Evidentemente, isso se deu por uma razão muito clara: Cuba vive a partir de 1959 o processo revolucionário, enquanto o Brasil em 1964 sofre o golpe que implantou a ditadura militar no país; sistemas políticos antagônicos que inviabilizaram relações entre os dois países, inclusive do ponto de vista científico. Entretanto, no período em que as relações entre os dois países começam a acontecer, no Brasil, os anos de 1984 e 1985 foram divisores de águas, pois se vivia os últimos momentos de uma ditadura militar que havia se iniciado nas duas décadas passadas. O fracasso do modelo político e econômico adotado pelo regime militar, bem como suas ações contra a população, levou a uma crescente onda de descontentamento popular. Em janeiro de 1985 as forças construídas nas alianças políticas conseguiram eleger Tancredo de Almeida Neves ${ }^{2}$ como presidente da Nova República (Fausto, 1997), pondo fim ao regime militar brasileiro e retornando a uma democracia que parece estar sempre ameaçada nos movimentos oscilatórios da política e do poder.

Nesse contexto a geografia brasileira vivia em efervescência. A abertura política, a descrença que muitos geógrafos passaram a ter em relação à Nova Geografia -Geografia Quantitativa - a falência do sistema de planejamento, a acentuação dos problemas nacionais que o regime militar tinha se proposto a solucionar, foram fatores que urgiram à necessidade de repensar o desenvolvimento de uma geografia que estivesse comprometida com os interesses sociais dos trabalhadores rurais e urbanos, e com um projeto histórico de transformação da sociedade. Esse quadro foi propício para que os geógrafos procurassem novos caminhos para a renovação da ciência geográfica.

Tudo isto iria contribuir para a emergência de uma Geografia Nova, também denominada de Geografia Crítica (Moura et al. 2008). A intensificação da Geografia Crítica no Brasil ocorre a partir da segunda metade dos anos de 1970, tendo no Encontro Nacional de Geógrafos Brasileiros ocorrido em Fortaleza no ano de 1978 - promovido pela Associação de Geógrafos Brasileiros-, um marco forte de expansão dessa corrente em nível nacional, “(...) sendo o encontro seguinte, o de 1980, no Rio de Janeiro, a vitória dessa corrente frente às tendências existentes" (Evangelista, 2014:323). Segundo Gonçalves (1982:94): "Neste momento se discutem os impasses gerados pelo próprio projeto da

2 Tancredo de Almeida Neves, não chegou a assumir a presidência da República. Por complicações de saúde, faleceu pouco tempo depois das eleições em 21 de abril de 1985, assumindo o vice-presidente José Sarney. 
AdÉLIa APARECIDA dE SOUZA HARACENKo

geografia enquanto um segmento do saber científico capaz de dar conta, compreender e explicar, enfim, os problemas concretos que se inscrevem no espaço geográfico em que vivemos".

Com a abertura política brasileira, o marxismo passa a ser uma filosofia de referência na geografia que procurava compreender o que havia passado e o que estava ocorrendo no Brasil e no mundo naquele contexto. Entretanto, como aponta Moreira (2000:35):

É verdade que respirando um ar impregnado da crítica marxista aos coveiros neopositivistas e estruturalistas da história, a renovação da geografia nasce tatibitateando a linguagem de Lefebvre, Althusser, Gramsci e Lukács, este introduzido pelos trabalhos de Armando Corrêa da Silva. A vertente marxista, mesmo que hegemônica, é entretanto uma vertente.

Ao marxismo e a suas diversas vertentes que se debruçaram a pensar o espaço geográfico no capitalismo, se junta outras perspectivas teóricas como a fenomenologia. Nessa conjuntura de renovação, uma plêiade de geógrafos vai dedicar-se em suas pesquisas e textos à compreensão do papel teórico e prático da geografia naquele momento. Dentre tantos textos importantes, três deles são retratos daquela conjuntura: O livro Por uma Geografia Nova de Milton Santos, o texto A Geografia está em Crise. Viva a Geografia de Carlos Walter Porto Gonçalves e o texto A Geografia Serve para Desvendar Máscaras Sociais de Ruy Moreira, estes publicados em 1978 e, posteriormente, os dois últimos também em 1982.

É, pois, nessa ebulição da renovação e, de suas próprias críticas, que começaram as relações dos geógrafos brasileiros com os cubanos. As figuras responsáveis pelo início desses vínculos geográficos no final dos anos da década de 1980 foram os professores: José Manuel Mateo Rodríguez, ${ }^{3}$ Arturo Rua de Cabo de Cuba ${ }^{4}$ e Cláudio Antônio Di Mauro do Brasil. ${ }^{5}$ Cada um destes professores relatou como foi o encontro entre os geógrafos e geografias. O professor Mateo Rodríguez, situou o início destas relações no contexto da sua trajetória intelectual:

Eu me formei em Cuba, no Bacharelado que lá é Licenciatura, no ano de 1970. Aí entrei para trabalhar na Faculdade de Geografia, lecionei primeiro, Geografia Física de Cuba. Então, eu comecei a trabalhar na tese de mestrado e doutorado, com professores soviéticos. O professor Ignatiev da Universidade de Moscou esteve em Cuba com a gente, percorremos parte do país. Finalmente eu fui para

30 professor José Manuel Mateo Rodríguez foi uma pessoa fundamental para o desenvolvimento dessa pesquisa, nos recebendo em suas residências tanto no Brasil quanto em Cuba. Forneceu-nos entrevistas -as quais foram a espinha dorsal dessa investigação- materiais e muito aprendizado. Pouco tempo após nossos últimos contatos a geografia Latino-americana perdeu o professor, que vinha lutando contra um câncer, cujo falecimento ocorreu na noite de 26 de julho de 2019 na cidade de Havana, logo após retornar do Brasil, onde estava trabalhando como professor visitante na Universidade Federal de Santa Maria no Rio Grande do Sul.

4 Arturo Rua de Cabo é professor na Faculdade de Geografia da Universidade de Havana. Dedica-se em seus estudos ao planejamento e ordenamento territorial e ao desenvolvimento regional. Concedeu-nos a entrevista nas dependências da Faculdade no dia 14 de janeiro de 2019.

50 professor Cláudio Antônio Di Mauro, no início das relações com os geógrafos cubanos, era professor na Universidade Estadual Paulista (UNESP) campus da cidade de Rio Claro, atuando na área de geomorfologia e planejamento ambiental. Na ocasião do nosso contato era professor da Universidade Federal de Uberlândia. Concedeu-nos a entrevista nas dependências do Departamento de Geografia da UNESP, campus da cidade de Presidente Prudente no dia 19 de outubro de 2018. 
União Soviética no ano de 76 [1976] e defendi minha tese de doutorado sobre a Paisagem de Cuba no final do ano de 1979, lá em Moscou. Voltei para Cuba no ano 80 [1980] e recomecei a trabalhar no departamento da Faculdade. Lá, fui chefe de departamento e comecei a ensinar, além de Geografia Física de Cuba, comecei a ensinar Paisagem. Aí publiquei meu primeiro livro no ano de 84 [1984] e comecei a trabalhar no Planejamento (J.M. Mateo Rodríguez, entrevista pessoal, 3 de setembro de 2018). ${ }^{6}$

Sobre sua experiência com os geógrafos de outros países da América Latina, o professor assinala que ela começa como sua participação em um Congresso em Bogotá da Rede Latino-Americana de Formação Ambiental no ano de 1985. No entanto, seus contatos com os geógrafos do Brasil começam a partir do ano 1986:

No ano 86 [1986] eu acho -já tinha terminado a ditadura brasileira por aí, mais ou menos- pela primeira vez, foram [a Cuba] três geógrafos brasileiros, da USP. Eu me lembro bem que eram três novos, três caras jovens. Eles tiveram uma reunião com a gente, acho que estava aí Tonico -Antonio Carlos de Moraes-e, mais dois. Mas foi uma conversa muito formal (J.M. Mateo Rodríguez, entrevista pessoal, 3 de setembro de 2018).

Depois desta aproximação com os geógrafos de São Paulo, Mateo Rodríguez salienta a relevância que teve a organização de um evento sobre o Meio Geográfico no ano 1988 em Cuba para afirmar as relações com a geografia brasileira.

Depois, no ano 88 [1988], nós em Cuba -eu estava de decano no departamento da Faculdade porque o decano estava em Moscou fazendo doutorado, e eu estava de substituto dele- organizamos um evento sobre o Meio Geográfico (...) convidamos gente da América Latina e foram várias pessoas de México, Venezuela, Colômbia, Nicarágua e sessenta e seis brasileiros. Era já o começo do relacionamento diplomático entre Cuba e Brasil. Nisso os brasileiros estavam loucos para conhecer a experiência cubana porque não sabiam nada [sobre ela] (...). O evento foi muito engraçado, porque foi em um lugar afastado da Universidade, na periferia da cidade -em um [tipo] convento que a gente tinha-, e aí ficaram todos alojados e, nós fomos para lá e ficamos com eles. Aí, foram três ou quatro dias de debate teórico, nós apresentamos nossa visão do meio ambiente cubano e todos eles apresentaram diferentes trabalhos. Depois, nós ficamos duas semanas ou dez dias, rodando pelo ocidente do país. Pegamos um ônibus com esse pessoal e andamos pela parte ocidental de Cuba, pela Havana e pela parte de Matanzas, aí eles conseguiram conhecer a realidade do projeto de transformação da natureza e do espaço. Foram vários geógrafos que agora são muito famosos, mas a liderança lá foi de Cláudio Di Mauro. Ali estava [também] Fani Alessandri. Tinha muita gente que está agora entre os grandes geógrafos brasileiros. Então, o Cláudio foi o cara! (...) O evento foi muito gostoso, além de debates, explicações práticas, a gente teve muito relacionamento, ainda que nós não compreendêssemos muito bem o português e eles também não compreendiam nem Cuba e nem o espanhol. Mas foi muito bom! Então, Cláudio falou para nós que ele tinha organizado o EGAL [Encontro de Geógrafos da 


\begin{abstract}
América Latina], o primeiro lá em Águas Claras, 'no estado de São Paulo, e que o segundo era para ser organizado em Montevidéu. Ele prometeu convidar dois cubanos e, foram dois cubanos. Eu não fui! Foram Arturo e outro professor que fez doutorado com o Cláudio (J.M. Mateo Rodríguez, entrevista pessoal, 3 de setembro de 2018).
\end{abstract}

Por seu lado, Rua de Cabo reconheceu que sua participação no EGAL de Montevidéu -a partir do convite do professor Di Mauro- abriu a possibilidade de viajar para o Brasil (entrevista pessoal, 14 de janeiro de 2019). Ele comentou com certo orgulho de ter sido o primeiro geógrafo cubano que vai retribuir a visita aos geógrafos do Brasil e dar sequência nas relações iniciadas em 1986 entre os geógrafos dos dois países:

Fiz meu primeiro contato com a geografia brasileira em 1989. Eu estava participando do segundo EGAL em Uruguai. Aí conheci e contactei com Cláudio Di Mauro, e ele fez um convite à gente para visitar Brasil. Visitei Brasil durante uma semana e fiz contato com o comando de Rio Claro em São Paulo. Estive uma semana em contato com eles e aí começou todo o peregrinar nosso, pelo Brasil. Cláudio Di Mauro me introduziu na geografia brasileira e, fundamentalmente, na geopolítica do Brasil e na geografia política brasileira. Eu comecei junto com Mateo os primeiros passos e, nessa direção, trabalhamos muito e nós contribuímos na tomada de posição de Cláudio, como comandante de Rio Claro (A. Rua de Cabo, entrevista pessoal, 14 de janeiro de 2019).

Por sua vez, o professor Di Mauro situa sua aproximação à geografia cubana no quadro de seus interesses políticos e ideológicos pelas transformações que provocou a revolução cubana:

Eu fui à Cuba pela primeira vez para participar de um evento. Eu sempre tive muito interesse em Cuba, evidentemente pelas minhas relações políticas e ideológicas e, eu fui à Cuba para conhecer um pouco o país e circular por lá. E lá eu fiquei conhecendo os professores da Universidade de Havana e do Instituto de Geografia: o professor Mateo, o professor Arturo Rua de Cabo, a professora Luisa B. Iñiguez Rojas, enfim, todos os professores lá da universidade. E aí então fiz um contato com o Mateo e com o Arturo para saber se eles gostariam de vir ao Brasil para iniciar um relacionamento de possibilidades. Aí montei um projeto pela FAPESP [Fundação de Amparo à Pesquisa do Estado de São Paulo]. O primeiro projeto com financiamento da FAPESP foi na UNESP de Rio Claro. E foi quando o Mateo veio pela primeira vez para o Brasil para, justamente, ministrar uma disciplina, Tópicos Especiais, no programa de pós-graduação da UNESP na geografia, no departamento de planejamento regional que estava sob a direção do professor Miguel Cézar Sanches e do professor Antonio Olívio Ceron. Nesse momento nós tínhamos acabado de organizar o primeiro Encontro de Geógrafos da América Latina [EGAL]. Nossa insatisfação era com o fato de a gente não ter diálogo com os geógrafos da América do Sul e da América Latina como um todo. Então fizemos o primeiro evento lá em Rio Claro que na verdade aconteceu em Águas de São Pedro e, eu senti a ausência do pessoal de Cuba. Não tinha Cuba! E, com isso então, eu resolvi passar a participar de um curso que foi

7 Esse primeiro EGAL ocorreu em 1987 na cidade de Águas de São Pedro, no estado de São Paulo. 
AdÉLIA APARECIDA dE SOUZA HARACENKO

oferecido lá, pela Universidade de Havana, e fiquei lá durante duas semanas e fiz um percurso pelo país. Aí então convidamos o Mateo para vir ministrar essa disciplina Tópicos Especiais. Ele permaneceu com a gente lá, acho que de dois a três meses em Rio Claro. Foi quando também ele conheceu o Cezar Leal. ${ }^{8}$ (C. Di Mauro, entrevista pessoal, 19 de outubro de 2018).

Em síntese, podemos afirmar que a abertura democrática no Brasil e a emergência da Geografia crítica provocou um interesse por descentrar o olhar disciplinar da França para a geografia Latino-americana. Neste quadro, estabelecem-se os primeiros vínculos entre a geografia cubana e brasileira a partir dos contatos entre os geógrafos da Universidade de Havana e da UNESP de Rio Claro.

\section{A intensificação dos vínculos a partir dos anos de 1990}

Nos anos de 1990 se intensificam as relações entre os geógrafos brasileiros e cubanos. A expressão disso é, por um lado, o crescimento dos contatos, particularmente, entre os professores das Universidades do Norte, Nordeste e da cidade de Rio Claro no Brasil com os da Universidade de Havana. Por outro, o conhecimento pessoal e da obra de Milton Santos entre os professores cubanos. Para muitos deles a conferência inaugural deste geógrafo brasileiro no V EGAL em Havana foi uma maneira de se aproximar das suas contribuições à ciência geográfica.

\section{Os encontros entre geógrafos de Havana e os de Rio Claro, Ceará e Piauí}

Mateo Rodríguez salienta que o fato de ter sido convidado para fazer pós-doutorado na Universidade de Rio Claro com o professor Di Mauro permitiu fortalecer as relações entre eles, bem como, com outros professores e suas linhas de pesquisa.

No ano de 92 [1992], ele [Di Mauro] falou para convidar a gente para ir para Rio Claro. Aí eu fui para lá -eu e Arturo-. Fiquei quatro meses lá fazendo pós-doutorado sem dinheiro no bolso porque na época era aquele negócio da hiperinflação de Collor de Mello. ${ }^{9}$ Fui -acho que- quatro vezes lá em Rio Claro. Eu e Arturo ministramos aulas, trabalhamos com o pessoal lá, no Departamento de Planejamento e publicamos algumas coisinhas. Eu tinha relacionamento com vários geógrafos brasileiros, fundamentalmente Antonio Christofoletti. Tinha muita conversa com ele (...). Então, Cláudio finalmente, na terceira viagem da gente, acho que no ano 96 [1996] mas não lembro, ele se candidatou para prefeito. Então, nós ministramos cursos sobre Planejamento Ambiental Urbano

80 professor Antonio Cezar Leal é também um dos responsáveis pelos vínculos entre os geógrafos brasileiros e cubanos durante sua trajetória acadêmica, mediante relações de amizades e pesquisas. A partir do ano de 1992, ainda como estudante de mestrado sob orientação do professor Cláudio Antônio Di Mauro, conheceu e intensificou sua relação com o professor Mateo Rodríguez, após cursar disciplina por ele oferecida na UNESP de Rio de Claro e conhecer sua metodologia de trabalho com bacias hidrográficas e questões ambientais. Tem como linhas de trabalho: gerenciamento de recursos hídricos, resíduos sólidos urbanos e planejamento ambiental de bacias hidrográficas. Recebeu-nos nas dependências do departamento de Geografia da UNESP de Presidente Prudente, onde é professor, e nos concedeu a entrevista no dia 29 de outubro de 2018.

9 Refere-se ao período em que Fernando Affonso Collor de Mello esteve como presidente do Brasil, de março de 1990 até o seu pedido de renúncia em dezembro de 1992. Mesmo após renunciar, sofreu o processo de impeachment. 
e fizemos um diagnóstico ambiental da cidade de Rio Claro, que ele utilizou para seu projeto de governo. Nesse interim, eu voltei para Cuba (J.M. Mateo Rodríguez, entrevista pessoal, 3 de setembro de 2018).

Nesse contexto se dá também o princípio das relações entre os professores cubanos e o professor Edson Vicente da Silva, ${ }^{10}$ da Universidade Federal do Ceará. Da Silva descreve desta maneira o atrativo político, social e cultural que provocou sua primeira viagem para Cuba.

Em meus percursos e viagens sempre ouvi falar de Cuba e sua proximidade étnico-cultural com o povo brasileiro. E, ademais, o Caribe e as Antilhas, regiões turísticas e paradisíacas praticamente intangíveis para mim durante meus passos como viajante. Havia ainda a Cuba como nossa referência libertadora e de não submissão latino-americana ao poderio norte-americano que se estendia como uma mancha de óleo sobre todos os países do continente. (...) Por fim deixei um carnaval, por quarenta dias em Cuba, em pleno período especial, fevereiro de 1992. Apesar da crise, o país e seu povo me tocaram a alma, o coração e principalmente minha consciência e ciência política de ser um afro latinoamericano, na mistura básica indígena, africana e ibérica. Percebi, compreendi e admirei nossa identidade comum, Brasil/Cuba, junto a outros países como Colômbia, Panamá e Venezuela, entre outros. Depois de trinta dias percorrendo Havana e seu entorno, durante pleno período especial, aprendi junto aos cubanos a arte do malabarismo, de como sobreviver sob tais condições de embargo econômico (E.V. da Silva, entrevista pessoal, 22 a 29 de julho de 2018).

Neste cuadro, da Silva detalha seu encontro com os professores Mateo Rodríguez e Rua de Cabo em Havana e o convite que lhe foi feito para dar uma palestra para os alunos de Geografia na Universidade desta cidade.

Bom, aí eu fiquei quarenta dias. Quando faltavam dez dias ainda para findar a viagem -como eu fiquei mais na região de Havana, Pínar del Río- então me deparei na Faculdade de Geografia que na época era bem afastada de Havana. (...) O professor Mateo e o professor Arturo já tinham vindo ao Brasil e tinham um contato muito forte com a UNESP de Rio Claro através do professor Cláudio Di Mauro; aí eu falei que era professor lá na UFC e que tinha interesse que eles fossem lá. Eles perguntaram também, eu falei que sim, que a gente podia tentar abrir uma cooperação. O Mateo perguntou se eu poderia dar uma palestra lá, e aí no outro dia eu já fui dar uma palestra para os alunos... incrível que foi em um dia de uma chuva imensa. Eu cheguei -maior dificuldade para chegar- consegui transporte e cheguei, assim, cinco minutos antes do horário marcado. Cinco para as oito e eu entrei na sala de aula. Eram trinta alunos, estavam trinta alunos ali presentes. Então é uma coisa que marca um pouco a geografia cubana, a questão disciplinar, a questão de seriedade, a questão da dedicação que passa, que é um

100 professor Edson Vicente da Silva é conhecido na comunidade acadêmica pelo apelido de Cacau. Atua em suas pesquisas nas seguintes temáticas: análise e educação ambiental, litoral, análise geoambiental recursos hídricos e desenvolvimento sustentável. Tomamos conhecimento de como se deu o início dessas relações com a geografia cubana em uma viagem que fizemos para a cidade de Fortaleza para entrevistá-lo. Durante a semana de 22 a 29 de julho de 2018 permanecemos na residência do professor, acolhida pela sua família no maravilhoso estilo do povo nordestino. 
foco do sistema educacional cubano né! Acho que o grande potencial de Cuba é seu potencial humano, hoje é o país com maior potencial humano da América Latina. Eles são muito exigentes com relação à educação e aí, claro, também são latinos, são como nós brincalhões e tudo, mas há uma seriedade muito grande. Nós conversamos, apresentamos todos sentados no chão, eu apresentei... foi um momento assim para mim muito importante esse primeiro contato com a geografia cubana e a partir daí, já começamos a percorrer Cuba (E.V. da Silva, entrevista pessoal, 22 a 29 de julho de 2018).

Por seu lado, Mateo Rodríguez refere da seguinte maneira ao seu primeiro encontro com o professor da Silva na Universidade de Havana, dando ênfase ao trabalho conjunto que começa a realizar com ele e com Di Mauro para difundir as linhas de pesquisa da geografia cubana no Brasil.

(...) estava lecionando e um dia, Cacau chegou em uma tarde lá em Havana, perguntando pela Paisagem, quem lecionava Paisagem. Acho que foi no ano de 93 [1993], por aí. ${ }^{11}$ Eu, justamente, estava lecionando Paisagem. Aí ele chegou e, eu sentei ele com a turma e falei: o que é para tu Paisagem? Ele se sentou, do jeito que ele é, e começou a falar. Aí começou meu relacionamento com Cacau, tudo bem! Eu vou falar de Cacau. Todo mundo conhece Cacau. Quando eu voltei, eu acho que no ano 93-94 [1993-1994] o Cacau levou a gente para Ceará, Arturo e eu. Fomos para lá, lecionamos e tivemos muito com os alunos, e foi muito bom! Um relacionamento muito bom! A esse relacionamento se juntou Agostinho, ${ }^{12}$ que na época estava fazendo o doutorado em Rio Claro, e depois foi professor da UFPI -ele faleceu-. Aí nós começamos a publicar várias coisas. Nesse interim, entre Cláudio Di Mauro e Cacau tivemos oportunidade de participar em vários eventos: em São Paulo, no ano de 92 [1992], um evento do Novo Mapa do Mundo do Milton -aí conheci Milton e conheci muita gente- e eventos da AGB em Curitiba. Eu fui convidado para várias palestras lá em Mato Grosso, em Cuiabá, com um pessoal que conhecia o Cláudio. (...) finalmente, fomos também para Santa Catariana e aí começamos nosso relacionamento. Daí eu comecei a ter muito contato com geógrafos brasileiros, me convidavam basicamente para o Congresso de Geografia Física Aplicada! Fui a vários eventos! (J.M. Mateo Rodríguez, entrevista pessoal, 3 de setembro de 2018).

O professor da Silva salienta as práticas que permitiram afiançar a cooperação entre geógrafos cubanos e brasileiros a partir de relações iniciais que vincularam a Faculdade de Geografia da Universidade de Havana, o Instituto de Geociências e Ciências Exatas da Universidade de Rio Claro, e os Departamentos de Geografia das Universidades Federais do Ceará e Piauí. Entre elas assinala os vínculos estabelecidos durante a sua formação doutoral na UNESP de Rio Claro e o convite feito aos professores Rua de Cabo e Mateo Rodríguez, para dar aulas e fazer pesquisas nas universidades do Norte e Nordeste do Brasil.

11 Conforme entrevista, o professor Edson Vicente da Silva chegou em Cuba em fevereiro de 1992

12 Faz referência ao professor Agostinho Paula Brito Cavalcanti, que foi professor da Universidade Federal do Piauí, com o qual também desenvolveu trabalhos de pesquisa. 
Após 1992, Arturo e Mateo, que já possuíam parcerias científicas com a UNESP de Rio Claro por meio do professor Cláudio Di Mauro, foram também convidados pela Universidade Federal do Ceará e pela Universidade Estadual do Ceará para atuarem como professores visitantes. Arturo esteve por dois períodos de seis meses, e Mateo algumas vezes mais, nos Programas de Pós-Graduação em Desenvolvimento e Meio Ambiente, Engenharia de Recursos Hídricos, e na Geografia [graduação/pós-graduação], na Universidade Federal do Ceará. Tive a oportunidade de realizar meu doutorado em Geografia na UNESP de Rio Claro, onde o colega Agostinho de Paula Brito Cavalcanti, professor do Departamento de Geografia da Universidade Federal do Piauí, também havia se formado e sido aluno de Arturo e Mateo. Esse foi, portanto, o núcleo inicial dessa cooperação científica na Geografia Brasil/Cuba, Nordeste/Ceará/Piauí, Faculdade de Geografia da Universidade de Havana, Departamento de Geografia da UFC [Universidade Federal do Ceará] e UFPI [Universidade Federal do Piauí] (E.V. da Silva, entrevista pessoal, 22 a 29 de julho de 2018).

A cooperação com o Brasil não envolveu apenas os geógrafos homens, também, a professora Luisa Basilia Iñiguez Rojas ${ }^{13}$ viajou para Rio de Janeiro no ano de 1994, deixando sua contribuição nas pesquisas geográficas, principalmente relacionadas com a geografia da saúde.

(...) Eu cheguei ao Brasil em 1994, em março, convidada pela FEEMA [Fundação Estadual de Engenharia do Meio Ambiente] - pelo diretor da FEEMA-, para trabalhar na Baixada Fluminense. Foi muito difícil a Baixada e [além disso] sem entender muito bem o português, nunca havia falado português e nem nunca estudei português. O contexto da Baixada Fluminense é bem complexo, como vocês sabem, qualquer um sabe. Eu trabalhei com uma socióloga e alguns estudantes da UFRJ [Universidade Federal do Rio de Janeiro], procurando entender a relação entre condicionante de vida e saúde, o perfil de morbidade e mortalidade na Baixada. E nunca vou esquecer que eu pedi uma reunião com o prefeito e com todos os secretários, e foi muito legal. Eu exigi deles, me revelar os problemas, os conflitos e foi assim impressionante. Por aí começou a fama de comandante, como depois me colocaram esse apelido [risos] (L.B. Iñiguez Rojas, entrevista pessoal, 22 de janeiro de 2019).

Iñiguez Rojas também abordou sobre o aprendizado com esse trabalho que desenvolveu no Rio de Janeiro na UFRJ -implicando relação entre condições de vida e saúde- bem como sobre o trabalho desenvolvido na Escola Nacional de Saúde Pública, vinculada à Fundação Osvaldo Cruz (Fiocruz). Por meio dessa entidade, ela permaneceu no Brasil até o mês de agosto de 1994, tendo oportunidade de trabalhar em pesquisas no Ceará e Manaus também com a geografia da saúde. Após o regresso a Cuba em agosto de 1994, novamente recebeu um convite da Fiocruz para retornar ao Brasil com o objetivo de que o relatório que ela havia escrito virasse um livro. Ela retornou e conseguiram publicar o material, o qual foi intitulado: Espaço e Doença: Um Olhar Sobre o Amazonas (1998), sendo este um sucesso para a Fiocruz e para o Ministério da Saúde. Nos anos seguintes

13 A professora Luisa Basilia Iñiguez Rojas, nos recebeu no dia 22 de janeiro de 2019 nas dependências da Faculdade Latinoamericana de Ciências Sociais (FLACSO) na cidade de Havana, onde ali concedeu-nos a entrevista. 
AdÉlIA ApARECIDA de SOUZA HaRACENKo

continuou desenvolvendo trabalhos no Brasil, dando aulas e palestras, principalmente em lugares remotos, e trabalhando quase sempre com comunidades carentes.

Os depoimentos recolhidos permitem compreender que os anos de 1990 aproximaram os geógrafos e geógrafas brasileiros e cubanos. Neste período formou-se um núcleo inicial de contatos entre especialistas e universidades. As relações envolveram práticas como: convites para ministrar palestras em um e outro país; para desenvolver-se como professores visitantes e levar adiante pesquisas acompanhadas de trabalho de campo nas áreas de meio ambiente, paisagem e geografia da saúde, sendo que as duas primeiras linhas de investigação já possuíam um longo caminho percorrido na geografia de Cuba.

\section{A influência da obra de Milton Santos na geografia de Cuba}

Para alguns professores, particularmente para aqueles que desenvolviam trabalhos em áreas como Geografia da Saúde, Demografia e Desenvolvimento, o conhecimento da figura de Milton Santos e de sua obra significou a incorporação de suas perspectivas nas suas próprias pesquisas. Nas entrevistas a alguns geógrafos cubanos, eles reconhecem que a primeira aproximação com Milton Santos foi através de sua produção intelectual. É o caso de René Alejandro González Rego ${ }^{14}$ e de Eduardo San Marful Orbis. ${ }^{15}$

Bueno, yo diría que mi primer vínculo no fue con geógrafos, sino con la producción científica de geógrafos brasileños. Fue para mis estudios de posgrado, o sea, para la formación doctoral, sobre todo en la construcción del capítulo teórico-metodológico en mi tesis, con la lectura de las obras del Milton Santos. O sea, no conocía Brasil ni a geógrafos brasileños personalmente, pero sí conocía la literatura de origen de autores brasileños (R.A. González Rego, entrevista pessoal, 14 de janeiro de 2019. Grifos nossos).

Mire... Esta pregunta que usted me hace me llena de satisfacción y de alegría ¿Por qué razón? Porque yo aprendí mucho cuando empiezo a conocer a Milton Santos. Para mí, Milton Santos es una de las grandes glorias de la geografía, no solamente brasileña, porque yo creo que Milton Santos (...) es de todo el continente, y Milton Santos va más allá del continente, es el geógrafo del mundo. (...) Consulté de Milton Santos gran parte de la bibliografia para mi trabajo de doctorado, esto me vinculó al pensamiento geográfico brasileño (E. San Marful Orbis, entrevista pessoal, 21 de janeiro de 2019. Grifos nossos).

Iñiguez Rojas aponta que a produção de Milton Santos foi ressignificada por ela, a partir do conhecimento pessoal deste geógrafo brasileiro.

140 professor René Alejandro González Rego nos recebeu em sua sala, na Faculdade de Geografia da Universidade de Havana, no dia 14 de janeiro de 2019, e ali nos concedeu a entrevista. As linhas de trabalho do professor são: Geodemografia e problemas socioambientais e urbanos.

150 professor Eduardo San Marful Orbis dedicou suas pesquisas à Geografia da População e Desenvolvimento. No ato desse trabalho estava vinculado ao Centro de Estudos Demográficos (CEDEM) da Universidade de Havana. Gentilmente se deslocou até a Faculdade de Geografia para que pudéssemos dialogar. Nossa conversa ocorreu no dia 21 de janeiro de 2019. Antes da publicação deste texto, também tomamos conhecimento do falecimento do professor San Marful, em decorrência de um câncer. 
adÉLIa APARECIDA de SOUZA HARACENKo

Mas para ser totalmente sincera, minha formação em geografia mudou quando achei o primeiro texto de Milton Santos [se emociona]. Bom! Quando eu o conheci, no ano 91 [1991], já ele sabia que tinha uma pessoa em Cuba muito interessada nele, e foi assim uma felicidade que ele me disse em uma entrevista em Toluca no Encontro de Geógrafo da América Latina. Ele chegou ao lugar (...) com um monte de livros na mão assim e, muitas pessoas em cima dele: "Ah! Dr. os livros"; e ele falou assim: "Não, os livros são para uma cubana, que os cubanos não têm dinheiro para comprar meus livros." Eu entrei naquela sala morrendo [risos], não sei... de medo, de..., mas na hora, compreendi que ia ser uma pessoa que ia iluminar meu roteiro, meu caminho pela geografia. $\mathrm{E}$ aconteceu isso mesmo. Ele me deu algumas dicas de como me desenvolver na geografia e ao final falou: "Estou feliz de que quando eu morra, já vai ter alguém que vai escrever sobre mim no Caribe.” (...) Começou esta história do espaço geográfico de Milton. Espetacular! (L.B. Iñiguez Rojas, entrevista pessoal, 22 de janeiro de 2019).

Inferimos que o conhecimento da produção de Milton Santos em Cuba motivou que ele fosse convidado para fazer a Conferência Inaugural do V EGAL celebrado em Havana no ano de 1995, intitulada: Nuevas Concepciones de la Geografía. Milton Santos sempre foi um dos grandes incentivadores, inspiradores e participantes assíduos deste evento. Assim descreve o geógrafo que participou na organização do evento, professor Roberto González Sousa: ${ }^{16}$

Yo fui secretario ejecutivo de ese encuentro. Tuvimos la posibilidad de invitar al profesor Milton Santos, que dio una conferencia magistral. En ese congreso -recuerdo porque estaba en todas las cuestiones administrativas, organizativas- (...) se alquiló un avión para traer a los brasileños aquí, y prácticamente nosotros tuvimos un congreso de más de 1200 personas. iFue grandioso! Pero para mí lo más importante fue el discurso de Milton, sus ideas y la enorme importancia que él otorgaba a la construcción social del espacio... todos los procesos territoriales, socio territoriales, la influencia que tuvieron en él toda una serie de geógrafos, filósofos, Lefebvre etc. Y para nosotros fue muy importante porque tuvimos una visión un poco distinta a la que habíamos adquirido en nuestros estudios anteriores, fundamentalmente (...) en la antigua Unión Soviética. Estos estudios tenían un contenido mucho más social y nos ayudó mucho a interpretar los procesos que hoy, todavía, seguimos estudiando (R. González Sousa, entrevista pessoal, 15 de janeiro de 2019).

Os geógrafos e geógrafas entrevistados falaram do impacto que teve a apresentação de Milton Santos nas suas reflexões e nas suas pesquisas geográficas, também apontaram que a obra dele teve uma forte influência nos estudos que desde então se realizam em Cuba. Enquanto González Sousa (entrevista pessoal, 15 de janeiro de 2019) afirma que se revisarmos as teses de licenciatura, mestrado e doutorado da Universidade de Havana constataremos menções à sua obra -seja ao descrever aspectos metodológicos ou de construir o conceito de espaço social-. Iñiguez Rojas (entrevista pessoal, 22 de

16 O professor Roberto González Sousa nos recebeu e concedeu a entrevista no dia 15 de janeiro de 2019, nas dependências da Faculdade de Geografia da Universidade de Havana, na cidade de Havana. Sua linha de trabalho está vinculada à geografia econômica, dedicando-se às questões sociais e territoriais. 
Os vínculos entre a geografia brasileira e...

AdÉLIA APARECIDA dE SOUZA HARACENKO

janeiro de 2019) assegura que a teoria do espaço geográfico de Santos foi adotada não só pelos geógrafos mas também por advogados, juristas, economistas, pelos estudos em farmácia, sociologia e bioética. Todos eles trabalham com as ideias de: espaços luminosos-opacos, de verticalidades-horizontalidades, de tempo espacial, entre outras.

Finalmente González Sousa, considera que o contato com Milton Santos lhes permitiu entrar também em contato com a produção de outros geógrafos e geógrafas do Brasil.

(...) y a partir de ese momento se inicia mucha relación. Milton nos invitó a participar en una mesa con él en Bauru y estuvimos en varios momentos en Brasil, invitados por la Asociación de Geógrafos Brasileños y por otras instituciones; eso me permitió seguir incrementando nuestro conocimiento, pero, además, empezamos a recibir mucha literatura del Brasil, (...) prácticamente casi todas las obras de Milton Santos, Christofoletti, toda una serie de geógrafos brasileños... empieza a llegar toda esa literatura que antes (...) no estaba a nuestro alcance. A partir de ese momento (...) las ideas de Milton y otros geógrafos de (...) su grupo de trabajo (...) fueron penetrando mucho en toda la geografia cubana (R. González Sousa, entrevista pessoal, 15 de janeiro de 2019. Grifos nossos).

Os contatos estabelecidos entre os geógrafos e geógrafas de Cuba, tanto com Milton Santos como com sua obra, nos permite aproximar do processo de circulação de ideias que tem lugar entre a geografia do Brasil e a geografia de Cuba -e para além da própria geografia-. Podemos reconhecer então, um processo de deslocamento de saberes acadêmicos que quebram a geopolítica do conhecimento estabelecida e que a desafia (viagens de ideias Norte-Sul, da Rússia à Cuba, da França ao Brasil). Nesta viagem, "la idea ya adaptada (o incorporada) por completo (o parcialmente) se ve hasta cierto punto transformada por sus nuevos usos, su nueva posición en un nuevo tiempo $y$ lugar" (Said, 2008:304).

\section{Os anos de 2000 e os projetos CAPES/MES-Cuba: sua importância na relação da geografia brasileira com a geografia cubana}

A partir dos anos 2000, o intercâmbio científico entre Brasil e Cuba, em várias áreas do conhecimento foi possível devido a políticas científicas de cooperação entre ambos os países, que outorga certa formalidade para aqueles contatos estabelecidos na década de 1990. Esse fato é apontado pelo professor Mateo Rodríguez:

(...) desde o ano 2000 para frente, aí o governo brasileiro e o governo cubano assinaram o convênio de inter-relação de projetos CAPES/MES, ${ }^{17}$ aí eu comecei

17 Segundo o Edital número 11 de 2007 da Coordenação de Aperfeiçoamento de Pessoal de Nível Superior (CAPES), "O Programa CAPES-MES/CUBA, apoiado no Protocolo assinado entre Brasil e Cuba em 19 de julho de 1996, tem como objetivo estimular, por meio de projetos conjuntos de pesquisa, o intercâmbio de docentes e pesquisadores brasileiros e cubanos, vinculados a Programas de Pós-Graduação de Instituições de Ensino Superior (IES), visando promover a formação de recursos humanos de alto nível 
AdÉLIA APARECIDA dE SOUZA HARACENKO

a trabalhar. Fizemos projeto com o Cacau, depois fizemos projeto com Ourinhos. Eu mobilizei muita gente e fiz um projeto muito grande com o pessoal da UFF [Universidade Federal Fluminense]. Então, houve este inter-relacionamento com o Brasil (J.M. Mateo Rodríguez, entrevista pessoal, 3 de setembro de 2018).

Mateo Rodríguez (2014) demonstrava certo otimismo a respeito da importância desta política científica tanto para Cuba quanto para o Brasil. Ele considerava que se tratava de uma aliança que visava à construção da sociedade do conhecimento. Do seu ponto de vista, na medida em que o modelo estatal baseado da União Soviética estava mudando, isto estava fazendo com que o país passasse a ter um socialismo original, diversificado e muito complexo. Neste quadro, Cuba vivenciava um momento de relações econômicas prioritárias com o Brasil, isso se manifestava, também, nos vínculos científicos.

No ano passado, tivemos a primeira reunião em Cuba-Brasil, associada ao conhecimento de cientistas brasileiros, tentando construir uma aliança para fazer uma plataforma encaminhada à questão da Sociedade do Conhecimento, a segunda reunião celebrou-se agora em conjunto no Brasil, e estamos tentando construir um projeto em conjunto. Procurar adequar à geografia cubana com os novos tempos da geografia mundial é o desafio que todos nós temos pela frente (Mateo Rodríguez, 2014:98).

O professor González Sousa faz a seguinte avaliação em relação ao significado desta política científica para a conformação de redes:

Desde 1995, desde el V Encuentro de Geógrafos hasta 2005-20o6 que empezamos con los proyectos CAPES, la relación fue a través de (...) participación en congresos. Profesores brasileños venían a Cuba, hacían breves estancias, algunos cubanos podríamos ir allá a congresos a los cuales nos invitaban. Así, se fueron creando los lazos. El inicio de los proyectos CAPES para nosotros fue fundamental. ¿Por qué digo que fue fundamental? Porque nos permitió empezar a asentar la posibilidad de organizar red de trabajos. De hecho, a partir de ese momento se crearon redes y el primer proyecto CAPES nuestro funcionaba, como se puede ver en los documentos, con varias universidades brasileñas: Presidente Prudente, Sergipe, Uberlândia, Paraná. O sea, había varias universidades que estaban trabajando con nosotros, por supuesto, íbamos a esas universidades a hacer estancias que podría ser de un mes, de dos meses; algunos compañeros hicieron estancias de hasta seis meses, donde compartíamos (...), trabajábamos en campo (...), publicábamos (...) y bueno, socializamos nuestra visión desde Cuba con los colegas brasileños ( $\mathrm{R}$. González Sousa, entrevista pessoal, 15 de janeiro de 2019).

Na Universidade Federal do Ceará estes projetos foram extremamente importantes para formalizar seu vínculo com Cuba. Igualmente o foram para a UNESP de Presidente Prudente, que se agregou às universidades brasileiras que estabeleceram relações com

no Brasil e em Cuba, nas diversas áreas do conhecimento". Informação retirada de: http://capes.gov.br/ bolsas-e-auxilios-internacionais/pais/202-cuba/9584-mes-projetos

As entidades responsáveis pelo programa foram: pelo Brasil, a Coordenação de Aperfeiçoamento de Pessoal de Nível Superior (CAPES) do Ministério da Educação (MEC) e, por Cuba, a Direção de Relações Internacionais do Ministério da Educação Superior (MES). 
a Universidade de Havana através de projetos coordenados pelos professores Bernardo Mançano Fernandes e Eliseu Savério Sposito, bem como dos demais professores do departamento de Geografia desta instituição que a eles se juntaram nos projetos de pesquisa realizados em parcerias com professores cubanos.

Pela Universidade Federal do Ceará, o professor da Silva, comenta: "desenvolvemos projetos de cooperação CAPES/MES-Cuba, fizemos projetos de professor visitante para o professor Arturo e Mateo virem para cá, e sempre o professor Mateo teve uma maior vezes de vindas.” (E.V. da Silva, entrevista pessoal, 22 a 29 de julho de 2018).

Na UNESP de Presidente Prudente, se apresentaram vários projetos de trabalho conjunto; um deles liderado pelo professor Bernardo Mançano Fernandes. ${ }^{18}$ Em entrevista, ele apontou que ao longo de sua carreira sempre procurou investir nas relações internacionais, principalmente com países da América Latina e sempre fazendo estudos comparativos entre os países. Nesse processo de relações conheceu o professor cubano González Sousa em um EGAL que ocorreu na Colômbia. A partir de então, decidiram desenvolver um projeto em conjunto, cujo objetivo era estudar o período neoliberal no Brasil e o período especial em Cuba. Iniciaram esta pesquisa, posteriormente enviaram um projeto a CAPES e, com a aprovação, estudaram as experiências e os projetos de governo do Brasil e de Cuba. O grupo teve missões de trabalho nos dois países. Então Fernandes diz:

A experiência com Cuba foi muito, muito boa, porque nós recebemos professores e alunos de Cuba, e mandamos professores e alunos para lá. Então, comparar um país capitalista com um país socialista. Num primeiro momento eu me lembro que alguns colegas dos Estados Unidos (...) eles falavam: "Bernardo, mas (...) não dá para comparar", e eu falei "Não! Mas você compara coisas iguais e diferentes. Não! Mas é muito complicado.” (...) mas eu falei: "Mas nós construímos uma metodologia, e nós estamos fazendo." E eu fiquei muito satisfeito com o resultado. Então a relação com a geografia cubana foi uma relação muito interessante (B.M. Fernandes, entrevista pessoal, 29 de outubro de 2018).

Outro projeto apresentado pela UNESP de Presidente Prudente envolveu dois grupos de pesquisa: o GAsPERR (Grupo de Pesquisa Produção do Espaço e Redefinições Regionais) e o GEDRA (Grupo de Estudos Dinâmica Regional e Agropecuária), cujo título foi Redes urbanas, cidades médias e dinâmicas territoriais: estudos comparativos entre Brasil e Cuba, o qual que teve uma duração de 2011 a 2015. Com este projeto, os professores da UNESP fizeram missões de trabalho e pesquisa em Cuba e, de igual maneira, a universidade recebeu profissionais de Cuba que vieram em missões de pesquisa. Falando sobre o projeto que esteve sob sua coordenação, em entrevista o professor Eliseu Savério Sposito ${ }^{19}$ comenta que:

180 professor Bernardo Mançano Fernandes nos concedeu a entrevista, no dia 29 de outubro de 2018, em sua sala nas dependências do departamento de Geografia da UNESP de Presidente Prudente. 0 professor tem se dedicado aos estudos em desenvolvimento territorial na América Latina e Caribe, investigando os temas: teoria dos territórios, paradigmas da questão agrária e do capitalismo agrário, reforma agrária e movimentos sociais de luta pela terra.

19 O professor Eliseu Savério Sposito nos concedeu a entrevista nas dependências do departamento de Geografia da UNESP de Presidente Prudente no dia 19 de outubro de 2018. Sua linha de trabalho engloba a geografia urbana e econômica, atuando nos seguintes temas: território, pensamento geográfico, produção do 
Os vínculos entre a geografia brasileira e...

Em 2011 -se não me falha a memória- (...) a partir da intermediação do Cezar que tinha recebido aqui o Mateo Rodríguez várias vezes, ele disse que tinha pessoas lá, em Cuba, interessadas em fazer um projeto em conjunto e, a pessoa de lá, chama-se Eduardo San Marful Orbis que esteve aqui duas vezes trabalhando com a gente. (...) Então, pela amizade, pelo trabalho em conjunto entre o Cezar Leal e o Mateo né, veio essa possibilidade de fazer o trabalho com o Eduardo. Representando Cuba, teve ele e uma professora de Cienfuegos, que também esteve aqui, mas que é mais ligada à geografia rural. Ela esteve junto com a Rosângela Hespanhol e o Nivaldo num grupo de pesquisa chamado GEDRA (...). Então nós fizemos esse projeto, juntando esses dois grupos o GAsPERR e o GEDRA, que tem aí muita distância temática, nós trabalhamos com a geografia urbana, mais econômica, e eles trabalham com a geografia rural. Mas fizemos o projeto e fomos aprovados pela CAPES. Tivemos missões lá e missões cá (...)! Do ponto de vista da mobilidade das pessoas, nós tivemos bastante pessoas indo e bastante pessoas vindo também (E.S. Sposito, entrevista pessoal, 19 de outubro de 2018).

Desta experiência vivenciada com os geógrafos brasileiros da UNESP de Presidente Prudente, San Marful Orbis salienta:

(...) tuve la dicha de entrar en un proyecto CAPES con el profesor Mançano, Bernardo Mançano, (...) un gran profesor dedicado a la geografía de la agricultura y a todo lo que tiene que ver con el Movimiento Sin Tierra. Con Mançano estuve ahí dos o tres meses en Brasil, aprendí muchísimo (...). Junto con la profesora Angelina, de aquí de la Facultad de Geografía, aportamos mucho a esa relación entre los geógrafos cubanos y los geógrafos brasileños (...). Posteriormente (...) conocí a la profesora Carminha y al profesor Sposito. Es un matrimonio que no solamente los une el amor, sino que también (...) la profesionalidad. (...) en ese proyecto hicimos estudios sobre las ciudades intermedias, (...) estuvimos trabajando en tres ciudades, en tres provincias en Cuba: una en la parte occidental, que casualmente es en la provincia de Matanzas, cuya característica fundamental era la producción azucarera en aquel momento y la industria del turismo porque ahí se encuentra el mayor balneario, Varadero-. Posteriormente, (...) trabajamos en la provincia de Cienfuegos. La provincia de Cienfuegos tiene características completamente diferentes a la de Matanzas y a la de Camagüey, a la que también fuimos. Importante para mí resultó no solamente (...) lo que pude aprender, sino que, a partir de este proyecto, surge la posibilidad de que tres estudiantes fueran bajo una beca sándwich. Ahí ellos hicieron una estancia de aproximadamente un mes (...), eso les sirvió para complementar sus estudios de maestría y doctorado. (...) fue uno de Camagüey, (...) otro de Cienfuegos y (...) otro (...) de la Habana. (...) Una gran parte de los profesores de Presidente Prudente que estaban involucrados en este proyecto vinieron a Cuba y visitaron estas tres provincias. Igualmente, vinieron estudiantes de allá a terminar (...) sus estudios de doctorado, aprendiendo de las experiencias cubanas y las diferenciaciones que existían entre Brasil y Cuba. Fue muy hermoso, fue 
muy constructivo. (...) Particularmente, yo me siento muy agradecido de estos proyectos CAPES y, sobre todo, con sus directores, tanto Mançano como Sposito (E. San Marful Orbis, entrevista pessoal, 21 de janeiro de 2019).

Alguns professores que não participaram destes projetos reconheceram as repercussões dos trabalhos conjuntos nas próprias instituições, particularmente nos intercâmbios de ideias. É o caso de González Rego:

\section{(...) aunque yo no pertenecía a ningún proyecto (...) pienso que, para la Facultad de Geografia, han sido muy provechosos estos intercambios (...), sobre todo las visitas de los colegas brasileños acá, a la Habana, no solamente por el proyecto en que venían, (...) sino (...) los [cursos de] posgrado que impartían las charlas científicas. (...) A partir de ahí, yo pienso que se ha acentuado más la relación con Brasil y (...) mi admiración por la producción científica y por los colegas brasileños (R.A. González Rego, entrevista pessoal, 14 de janeiro de 2019).}

No ano 2018, o Brasil estava prestes a realizar as eleições presidenciais de 2018, uma das mais polarizadas de sua história, na qual entre os candidatos estavam aqueles que viam as relações com Cuba -ou com qualquer outro país com ideias socialistas- um perigo aos ideais do desenvolvimento capitalista. Ficou claro que, se a extrema direita fosse vencedora do pleito -fato que ocorreu-, essas relações estariam comprometidas. Mateo Rodríguez, prevendo tal situação, destacou sobre o fim do programa CAPES/MES:

Muito triste! Muito triste, porque esse relacionamento CAPES/MES, esse relacionamento que a gente tinha está acabando. A única possibilidade que nós cubanos temos de trabalhar aqui no Brasil, é trabalhar como professor visitante. (...) nós estamos numa situação que não tem financiamento, o país está lutando de novo, por resistir, (...) tentando transfigurar o sistema, de adequar o sistema socialista no mundo globalizado no século XXI. (...) minha experiência é que para ter um relacionamento como foi CAPES/MES, deve de ter uma vitória da esquerda brasileira e que isso, por enquanto, não vai acontecer (J.M. Mateo Rodríguez, entrevista pessoal, 3 de setembro de 2018).

Das análises realizadas, podemos concluir que a possibilidade de garantir a formação de circulação do conhecimento na América Latina e da construção de uma interpretação latino-americana das dinâmicas espaciais em curso, só pode ser assegurada através de uma vontade política que promova projetos científicos de cooperação. A chegada de Jair Bolsonaro ao governo do Brasil no ano de 2019 pôs fim a estes projetos de colaboração entre os geógrafos brasileiros e cubanos.

\section{Um balanço das relações institucionais}

Ao iniciarmos esta pesquisa, não tínhamos a dimensão da quantidade de universidades brasileiras -com seus geógrafos e geógrafas- que poderiam ter tido, ou estar tendo, vínculos com universidades, geógrafos e geógrafas de Cuba. Essa dimensão foi constatada após os trabalhos realizados com o professor da Silva. Ele relatou o que conhecia sobre as relações geográficas estabelecidas com Cuba em várias instituições de Norte a Sul do Brasil. 
Bom! É, eu vou começar do Sul para cima, né! Então, eu sei por exemplo, Santa Maria no Rio Grande do Sul, o professor Adriano Figueiró e o seu grupo, que também é da geoecologia da paisagem, (...). E, depois, eu sei que no Paraná a pessoa do Chico Mendonça, na Federal do Paraná, trabalha também com o professor Mateo, principalmente, o início de promover vários eventos de geografia física aplicada. A UNESP de Rio Claro, como já foi dito anteriormente, tem um grande contato e, atualmente, um grande polo de interação com Cuba; eu acho que, talvez, o mais forte que eu conheço é a UNESP de Presidente Prudente, através do professor Antonio Cezar Leal e seus colegas, seu grupo de trabalho com bacias hidrográficas. Depois temos o pessoal aqui mais perto, na UNICAMP, a professora Glória, que também tem esse intercâmbio com Cuba, muito forte. Pessoal da Federal Fluminense do Rio de Janeiro, professor Raul, que é cubano também, tem feito trabalhos em conjunto. Quem mais? E, depois subindo né, tem o professor Sakamoto também, que era da Universidade Federal de Três Lagoas. Deixa eu ver, se eu estou me lembrando... acho que o professor Jairo lá do Acre, da Federal do Acre, porque tive muitos professores de outros lugares que vem para cá. O professor da Universidade do Estado do Amazonas (...) Carlos Sandro de Albuquerque, que também vem trabalhando essa perspectiva da geoecologia da paisagem das áreas de Parintins no Amazonas das áreas fluviais. O professor Antônio Torino Veras da Federal de Roraima. O professor Lúcio Keury da Estadual de Roraima, que também temos trabalhado nesta perspectiva de geoecologia da paisagem, planejamento urbano, e com ele também a questão indígena, como fazer, por exemplo, a gestão de terras indígenas. (...) Bom! Depois seguindo, a gente tem a Federal do Pará, o professor Carlos Bordalo, que também trabalha com a questão de bacias hidrográficas, dentro da gestão sustentável. E, aí, temos em Marabá a professora Maria Rita Vidal e o professor Abraão que também trabalham com essa perspectiva de geoecologia da paisagem, na própria Federal do Pará, também em Ananindeua. O professor Lúcio Corrêa Miranda e a professora Luciana Freire que trabalham também na perspectiva da geoecologia da paisagem. O Professor Lúcio Miranda, é de São Tomé e Príncipe, fez o trabalho dele sobre o planejamento geoecológico da Ilha do Príncipe e depois terminou fazendo um concurso aqui; hoje ele é professor lá, é formado aqui na UFC. Nós temos o professor Otávio Landim que é professor da UNIFAP de Oiapoque e o professor Mauro Palhares que também temos feito grandes intercâmbios com Cuba. (...) No Maranhão nós temos o professor Leonardo Silva Soares que é da oceanografia, mas que também tem atuado nessa área de planejamento e gestão a partir da geoecologia. E, no Piauí, não posso deixar de falar do professor Agostinho Paula Brito Cavalcante que, infelizmente, ele é falecido, mas ele foi a pessoa que constituiu o grupo inicial desse intercâmbio. O primeiro livro que publicamos foi com o professor Agostinho, sobre planejamento e gestão. professor Agostinho, o Arturo, o Mateo e eu. Isso já seria Universidade Federal do Piaú. Seguindo, aqui em Rio Grande do Norte nós temos em Mossoró o professor Rodrigo Guimarães da Universidade Estadual do Rio Grande do Norte, que trabalha dentro do curso de gestão ambiental em Mossoró. E a professora Juliana Felipe Farias que é da Universidade Federal do Rio Grande do Norte dentro da geografia. E, esqueci de falar! Na Paraíba o professor da Federal da Paraíba, professor Giovanni de Farias Seabra que também trabalha nessa linha de geoecologia da paisagem 
Os vínculos entre a geografia brasileira e...

e, na Universidade Federal de Pernambuco, professor Lucivanio Jatobá, que inclusive fez e defendeu a tese dele baseado principalmente nos preceitos da geoecologia da paisagem (...). E não esquecer, aqui, especificamente no Ceará, eu acho que a influência cubana atinge todo o estado e todas as instituições, desde a Universidade Estadual e Federal do Ceará e seus cursos de geografia, né! Aí, eu vou citar dentro da geografia da Federal a minha pessoa, Edson Vicente da Silva, o professor Antonio Jeovah de Andrade Meirelles, a professora Adriane Gorayeb e todo corpo de alunos e mestrandos, doutorandos que se formaram. (...) Aí teria o professor Frederico de Holanda Bastos, que trabalhou com essa visão, enfocou na unidade de sistemas ambientais e, na UVA, o professor Ernane Cortez Lima. Então, foram pessoas (...) orientadas por mim e indiretamente pelo professor Mateo. Na região do Cariri temos as professoras Daniela Guerra e Juliana Maria de Oliveira, que também fizeram a pós-graduação aqui na UFC e desenvolvem essas áreas de conhecimento (...) (E.V. da Silva, entrevista pessoal, 22 a 29 de julho de 2018).

Baseado na fala do professor da Silva, digitalizamos as informações e confeccionamos um mapa das relações institucionais entre a geografia brasileira e cubana. Abaixo segue o mapa (Figura 1).

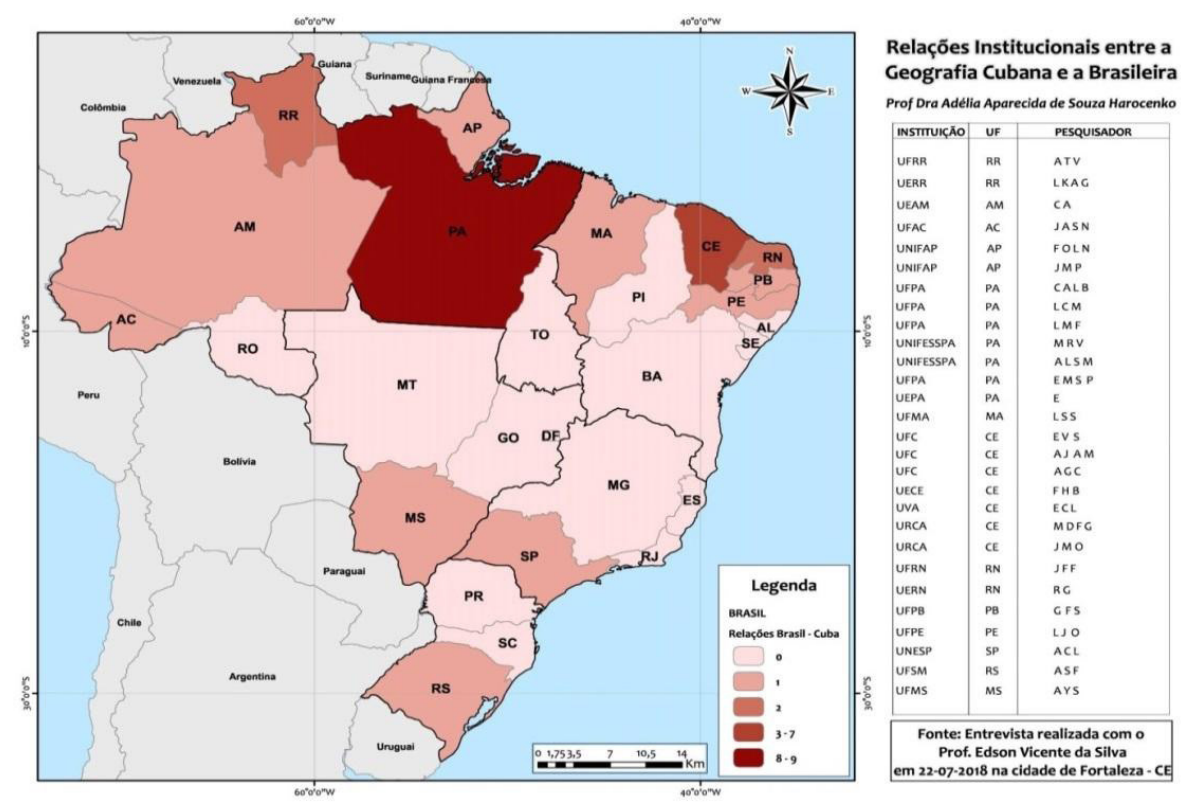

Figura 1. Relações Institucionais entre a Geografia Brasileira e Cubana. Fonte: informações extraídas das entrevistas com o professor E.V. da Silva (22 a 29 de julho de 2018).

Após as tarefas realizadas com o professor da Silva, e das informações por ele fornecidas, nos dedicamos aos trabalhos junto ao professor Mateo Rodríguez. Baseado em seus conhecimentos, ele elaborou uma Metodologia de Grau de Intensidade -a qual sintetizamos em um quadro- desenvolvida a partir da sua experiência de trabalho no Brasil, principalmente a partir dos anos de 1990, para avaliar o grau de relação e colaboração das universidades brasileiras com os geógrafos e geógrafas de Cuba (Quadro 1). 
Os vínculos entre a geografia brasileira e...

AdÉlIA ApARECIDA de SOUZA HaRACENKo

Quadro 1. Relação e Colaboração de Instituições entre Brasil e Cuba por Graus de Intensidade. Fonte: informações extraídas dos trabalhos com o professor José Manuel Mateo Rodríguez (entrevista pessoal, 3 de setembro de 2018).

\begin{tabular}{|c|c|c|c|c|c|c|c|c|c|}
\hline \multicolumn{2}{|c|}{$\begin{array}{l}\text { Intensidade de } \\
\text { Colaboração }\end{array}$} & 10 & 5 & 2 & 2 & 2 & 10 & $\begin{array}{c}\text { Fator } \\
\text { Multiplicador }\end{array}$ & \\
\hline Estado & Universidade & Projetos & Publicações & $\begin{array}{c}\text { Pós } \\
\text { Doutorado }\end{array}$ & $\begin{array}{c}\text { Doutorado/ } \\
\text { Mestrado }\end{array}$ & Cursos & P. V. & Intensidade & $\begin{array}{c}\text { Intensidade } \\
\text { por Estado }\end{array}$ \\
\hline \multirow{5}{*}{ SP } & $\begin{array}{l}\text { UNESP - Rio } \\
\text { Claro }\end{array}$ & 0 & 4 & 4 & 2 & 5 & 0 & 42 & \multirow{5}{*}{195} \\
\hline & $\begin{array}{l}\text { UNESP Pres. } \\
\text { Prudente }\end{array}$ & 1 & 4 & 5 & 2 & 10 & 0 & 64 & \\
\hline & $\begin{array}{l}\text { UNESP - } \\
\text { Ourinhos }\end{array}$ & 1 & 1 & 0 & 1 & 1 & 0 & 19 & \\
\hline & USP & 0 & 3 & 0 & 1 & 5 & 0 & 27 & \\
\hline & UNICAMP & 2 & 3 & 0 & 1 & 3 & 0 & 43 & \\
\hline \multirow{3}{*}{ RJ } & UFF & 2 & 1 & 2 & 2 & 5 & 0 & 43 & \multirow{3}{*}{87} \\
\hline & UFRJ & 2 & 1 & 2 & 0 & 3 & 0 & 35 & \\
\hline & UERJ & 0 & 1 & 1 & 1 & 0 & 0 & 9 & \\
\hline \multirow{2}{*}{ CE } & UFC & 2 & 10 & 4 & 4 & 2 & 0 & 90 & \multirow{2}{*}{104} \\
\hline & UECE & 0 & 0 & 1 & 1 & 5 & 0 & 14 & \\
\hline \multirow{2}{*}{ RS } & UFSM & 0 & 1 & 0 & 0 & 3 & 1 & 21 & \multirow{2}{*}{23} \\
\hline & UFRGS & 0 & 0 & 0 & 0 & 1 & 0 & 2 & \\
\hline SC & UFSC & 0 & 0 & 0 & 0 & 3 & 0 & 6 & 6 \\
\hline \multirow{2}{*}{ PR } & UFPR & 0 & 0 & 0 & 0 & 2 & 0 & 4 & \multirow{2}{*}{13} \\
\hline & UEPR & 0 & 1 & 1 & 0 & 1 & 0 & 9 & \\
\hline \multirow{3}{*}{ MS } & $\begin{array}{l}\text { UFGD - } \\
\text { Dourados }\end{array}$ & 0 & 2 & 1 & 2 & 2 & 0 & 20 & \multirow{3}{*}{72} \\
\hline & $\begin{array}{l}\text { UFMS - Três } \\
\text { Lagoas }\end{array}$ & 1 & 1 & 0 & 1 & 2 & 1 & 31 & \\
\hline & \begin{tabular}{|l} 
UEMS - \\
Aquidauana \\
\end{tabular} & 0 & 1 & 1 & 0 & 2 & 1 & 21 & \\
\hline SE & UFS & 1 & 2 & 0 & 1 & 2 & 0 & 26 & 26 \\
\hline PB & UFPB & 0 & 3 & 0 & 0 & 3 & 0 & 21 & 21 \\
\hline PI & UFPI & 0 & 2 & 1 & 0 & 4 & 0 & 20 & 20 \\
\hline PE & UFPE & 0 & 1 & 0 & 1 & 3 & 0 & 13 & 13 \\
\hline$A C$ & UFAC & 1 & 2 & 0 & 1 & 2 & 0 & 26 & 26 \\
\hline
\end{tabular}

A denominada Metodologia de Grau de Intensidade, utilizada para entendermos os graus de intensidade de vínculos da geografia brasileira com a geografia cubana, consiste no seguinte: primeiramente vemos os estados com as universidades que tiveram colaboração com Cuba. Na linha seguinte, temos as variáveis: projetos, publicações, pós-doutorado, doutorado e mestrado, cursos e a abreviação P.V. que significa professor 
Os vínculos entre a geografia brasileira e...

AdÉLIA APARECIDA dE SOUZA HARACENKO

visitante. Na linha acima temos os fatores multiplicadores, cujos valores foram utilizados, seguindo os seguintes critérios:

»10 para projetos, porque tem maior complexidade, possui recursos e resulta em intercâmbios.

》 5 para publicações, porque representam a produção acadêmica resultante dos intercâmbios.

» 2 para pós-doutorados, porque o pós-doutorado pode ser um trabalho acadêmico vinculado ao ensino e a construção teórica metodológica, cujo resultado vai estar ligado às publicações e outras atividades acadêmicas.

» 2 para mestrado/doutorado, porque grande parte desta formação está ligada ao esforço empírico e intelectual do sujeito e não aos projetos de intercâmbios.

" 2 para cursos, porque são transferências de conhecimentos.

》 10 para professor visitante, porque é um trabalho contratado que inclui um árduo trabalho com várias atividades, por exemplo, todo um trabalho de um departamento; cursos, aulas, burocracias etc.

O cálculo da intensidade de cada universidade é feito utilizando, primeiramente, a quantidade de projetos, publicações, pós-doutorado, doutorado e mestrado, cursos e P.V., multiplicando cada um pelo fator multiplicador. Ao final soma-se tudo e teremos então o grau de intensidade de cada universidade. Por sua vez, a intensidade por estado é o resultado da soma da intensidade de todas as universidades daquele estado. Abaixo segue os mapas resultantes do quadro desenvolvido pelo grau de intensidade (Figuras 2 e 3 ).

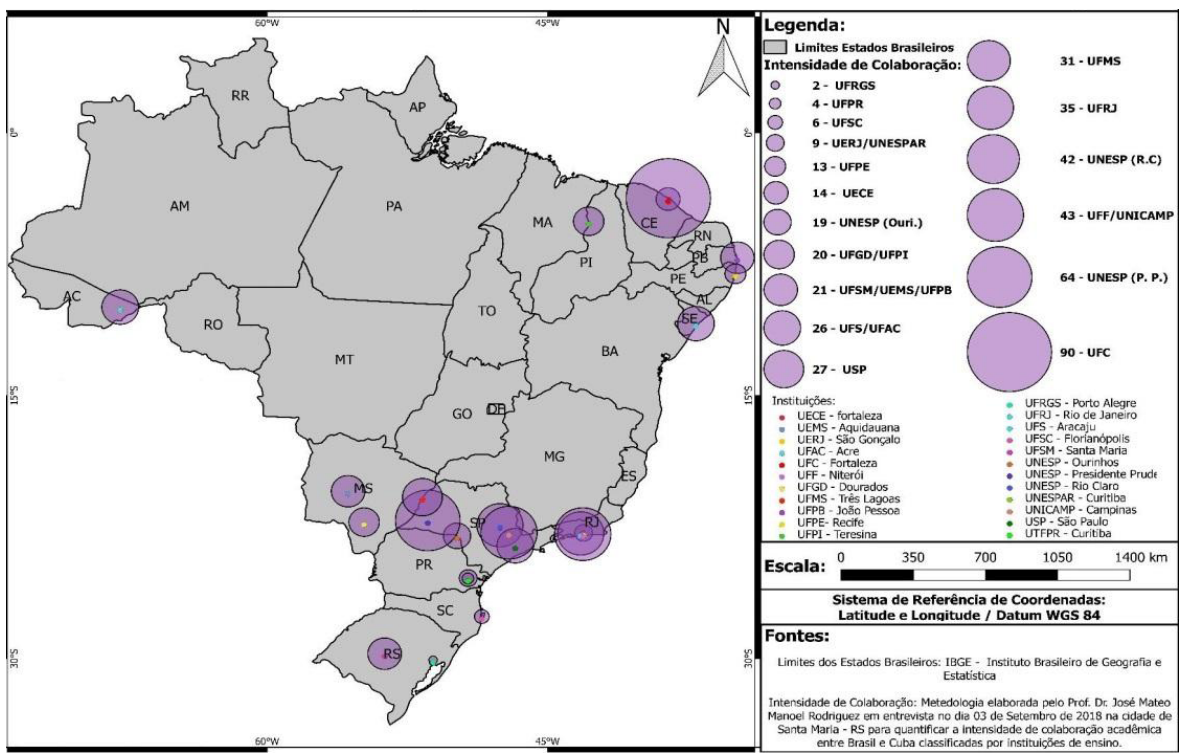

Figura 2. Intensidade de Colaboração Acadêmica entre Cuba e Brasil por Instituição. Fonte: informações extraídas dos trabalhos com o professor J.M. Mateo Rodríguez (entrevista pessoal, 3 de setembro de 2018). 


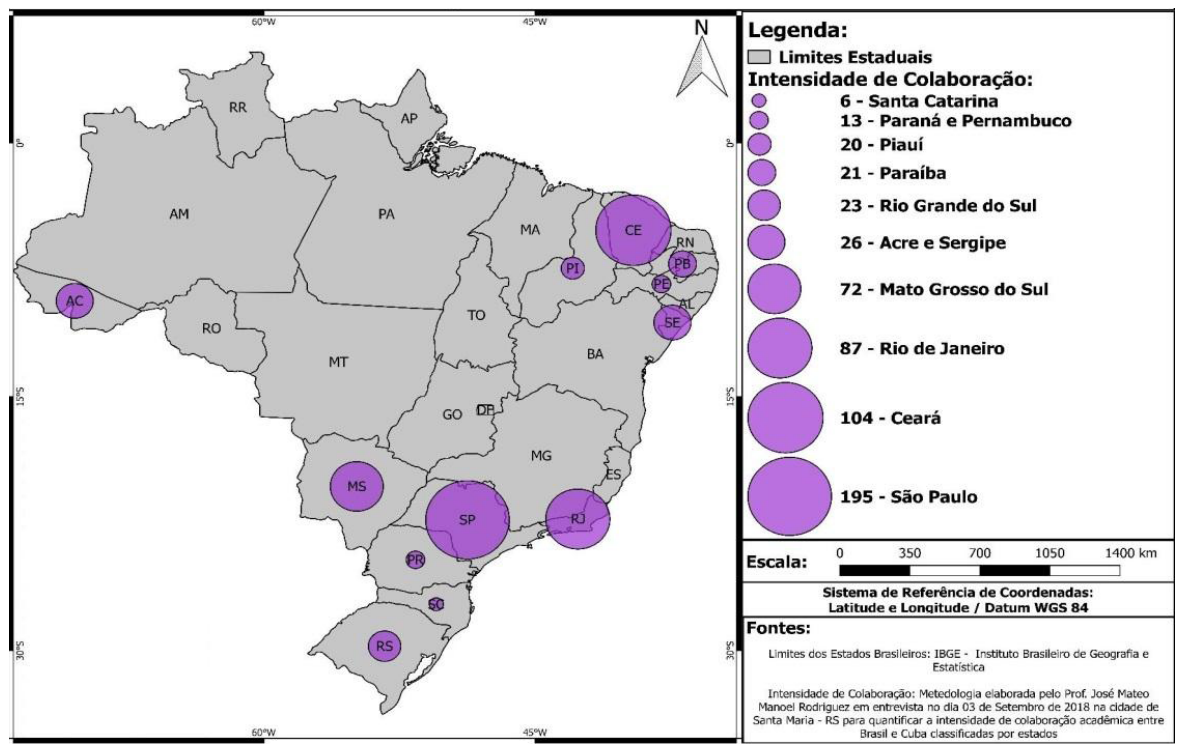

Figura 3. Intensidade de Colaboração Acadêmica entre Cuba e Brasil por Estado. Fonte: informações extraídas dos trabalhos com o professor J.M. Mateo Rodríguez (entrevista pessoal, 3 de setembro de 2018).

Podemos notar que na Figura 2, o grau de intensidade de colaboração entre as universidades brasileiras com Cuba recai fundamentalmente entre a Universidade Federal do Ceará e a UNESP de Presidente Prudente. De igual maneira na Figura 3, notamos que no mapa por estado, Ceará e São Paulo demonstram maior intensidade de colaboração entre os dois países.

Utilizamos a Metodologia do Grau de Intensidade também para avaliar a colaboração dos professores da Universidade de Havana com as universidades brasileiras, conforme demonstra o quadro seguinte.

Quadro 2. Intensidade de Colaboração dos professores da Universidade de Havana com as Universidades Brasileiras. Fonte: trabalho realizado com os professores da Faculdade de Geografia da Universidade de Havana.

\begin{tabular}{|l|l|c|c|c|c|c|c|c|}
\hline \multicolumn{1}{|c|}{ Intensidad de Colaboración } & $\mathbf{1 0}$ & $\mathbf{5}$ & $\mathbf{2}$ & $\mathbf{2}$ & $\mathbf{2}$ & $\mathbf{1 0}$ & \\
\hline Profesor & $\begin{array}{l}\text { Universidad de } \\
\text { Colaboración }\end{array}$ & Proyectos & Publicaciones & $\begin{array}{c}\text { Pós } \\
\text { Doctorados }\end{array}$ & $\begin{array}{c}\text { Maestria/ } \\
\text { Doctorado }\end{array}$ & $\begin{array}{l}\text { Cursos } \\
\text { José Manuel }\end{array}$ & $\begin{array}{l}\text { Profesor } \\
\text { Visitante }\end{array}$ & $\begin{array}{l}\text { Intensidad } \\
\text { UFSS } \\
\text { UFteo } \\
\text { UFF } \\
\text { Rodriguez }\end{array}$ \\
$\begin{array}{l}\text { UFRJ } \\
\text { UNICAMP } \\
\text { UFMT - Três } \\
\text { Lagoas }\end{array}$ & 10 & 28 & 9 & 19 & 43 & 1 & 392 \\
\hline $\begin{array}{l}\text { Arturo Rua de } \\
\text { Cabo }\end{array}$ & $\begin{array}{l}\text { UFC } \\
\text { UNESP }\end{array}$ & 2 & 1 & 1 & 2 & & 1 & 41 \\
\hline $\begin{array}{l}\text { Julio Iván } \\
\text { González } \\
\text { Piedra }\end{array}$ & $\begin{array}{l}\text { UFC } \\
\text { UNESP - Botucatu }\end{array}$ & 2 & 6 & & 6 & 5 & 6 & 132 \\
\hline
\end{tabular}


Os vínculos entre a geografia brasileira e...

AdÉlIA APARECIDA DE SOUZA HARACENKO

\begin{tabular}{|c|c|c|c|c|c|c|c|c|}
\hline \multicolumn{2}{|c|}{ Intensidad de Colaboración } & 10 & 5 & 2 & 2 & 2 & 10 & \\
\hline Profesor & \begin{tabular}{|c|}
$\begin{array}{c}\text { Universidad de } \\
\text { Colaboración }\end{array}$ \\
\end{tabular} & Proyectos & Publicaciones & $\begin{array}{c}\text { Pós } \\
\text { Doctorados }\end{array}$ & $\begin{array}{l}\text { Maestria/ } \\
\text { Doctorado }\end{array}$ & Cursos & $\begin{array}{l}\text { Profesor } \\
\text { Visitante }\end{array}$ & Intensidad \\
\hline $\begin{array}{l}\text { René } \\
\text { Alejandro } \\
\text { González Rego }\end{array}$ & UNB & 1 & 1 & & & 1 & 1 & 27 \\
\hline $\begin{array}{l}\text { José Evelio } \\
\text { Gutiérez } \\
\text { Hernández }\end{array}$ & $\begin{array}{l}\text { UNESP - Ourinhos: } \\
\text { Botucatu }\end{array}$ & 2 & 2 & 1 & 2 & 6 & 2 & 68 \\
\hline $\begin{array}{l}\text { Eduardo San } \\
\text { Marful Orbis }\end{array}$ & $\begin{array}{l}\text { UNESP - } \\
\text { Presidente } \\
\text { Prudente }\end{array}$ & 2 & 10 & 1 & 3 & 25 & 4 & 168 \\
\hline $\begin{array}{l}\text { Luisa Basilia } \\
\text { Iñiguez Rojas }\end{array}$ & $\begin{array}{l}\text { UFI } \\
\text { UNEMAT } \\
\text { USP } \\
\text { UNESP } \\
\text { UFAN } \\
\text { UFAC } \\
\text { UFPE } \\
\text { UNIR } \\
\text { UFRJ }\end{array}$ & 6 & 25 & & 2 & 15 & 15 & 369 \\
\hline $\begin{array}{l}\text { Juan Manuel } \\
\text { Fernández } \\
\text { Lorenzo }\end{array}$ & UNESP - Botucatu & 1 & 1 & & 1 & 1 & 1 & 29 \\
\hline
\end{tabular}

Neste quadro, notamos que a maior intensidade de colaboração recai sobre os professores Mateo Rodríguez e Iñiguez Rojas. Inferimos que isso está diretamente ligado ao maior período em que ambos se dedicaram aos seus trabalhos no Brasil, respectivamente a partir do final dos anos de 1980 e a partir do início de 1990.

\section{Redes acadêmicas ou círculos de afinidades?}

Nos diálogos que tivemos, tanto do lado de cá quanto do lado de lá do mar do Caribe, foi colocada aos geógrafos e geógrafas a pergunta se eles acreditaram que através dos anos foram-se construindo redes académicas. As respostas divergem.

Para alguns dos geógrafos brasileiros como Di Mauro, não poderia se afirmar que se conformou uma rede: "Nós temos os contatos, vamos dizer alguns pilares organizados e se estabelece um diálogo continuado" (entrevista pessoal, 19 de outubro de 2018). Segundo a avaliação do professor da Silva, a rede tem um caráter não formal: "Bom, eu acho que não existe, como que a gente pode dizer? Uma rede totalmente formal oficializada, mas existe uma rede que funciona, né!" (entrevista pessoal, 22 a 29 de julho de 2018). Já na UNESP o professor Fernandes prefere falar de pontes e não de rede:

(...) você me apresentou aqui um conjunto de universidades que têm projetos com Cuba, eu não conhecia, então assim: a UNESP tem uma ponte, a Federal do Ceará tem outra ponte, nós temos um conjunto de pontes, que cada um vai de uma ponta a outra, mas não se cruza, então não forma uma rede. (...) eu ministrei aula lá [Cuba], os professores que eu trouxe, eles ministraram aula aqui [Brasil]. Eles coorientaram aqui, eu coorientei lá, então eu diria que foi uma experiência completa, mas nós não conseguimos formar essa rede. Eu acho que ela está preparada, mas não está formada (B.M. Fernandes, entrevista pessoal, 29 de outubro de 2018). 
Por sua vez, o professor Sposito considera que o projeto que ele coordenou foi uma rede efêmera. Os trabalhos foram realizados, mas, quando o projeto findou, os contatos também desapareceram. Isto porque não houve uma continuidade. Neste sentido, se considera que houve construção de vínculos e colaborações de perspectivas analíticas comuns, de objetos de trabalho compartilhados, mas esta cooperação está diretamente ligada à questão financeira para o desenvolvimento das pesquisas. Porém, o professor Antonio Cezar Leal afirma que existem redes e que:

(...) às vezes tem uma formalização da rede e, outras vezes, ela acontece pelos contatos, pela amizade, pela interação que nós temos. Então, há uma rede sim de professores, muito ligados ao Mateo e, através do Mateo, se expandiu para vários outros professores (A.C. Leal, entrevista pessoal, 29 de outubro de 2018).

Entre os geógrafos cubanos as visões também são diferentes. Mateo Rodríguez afirma que seu projeto era construir uma rede acadêmica, porém, a mudança de governo dificultou concretizar este projeto.

Nós começamos a construir várias redes com o projeto CAPES/MES. (...) Nós tivemos -acho que- sete projetos, não! Foram muito úteis para todo mundo, porque nós começamos as redes de no mínimo quatro-cinco equipes de trabalhos. Aí começaram as redes. Só que infelizmente, há dois, três anos, esse relacionamento foi suspenso por causa da mudança de governo. Mas o vínculo da geografia cubana e brasileira acho que não é muito forte (...). Mas, eu acho que a geografia brasileira conhece muito pouco a geografia cubana e vice-versa. Então, o que acontece é que, por exemplo, o único vínculo que existe na geografia brasileira com a geografia latino-americana é basicamente através dos EGAL (J.M. Mateo Rodríguez, entrevista pessoal, 3 de setembro de 2018).

O professor Julio Iván González Piedra ${ }^{20}$ considera que esta rede, por enquanto, só tem uma existência virtual:

Yo creo que sí, existe una red, pero todavía esa red yo la considero virtual. Yo no considero que exista en la realidad, porque realmente no nos vinculamos, no dialogamos, no tenemos esa posibilidad, ese espacio no lo hemos construido. (...) no existe una red concreta, una red real (J.I. González Piedra, entrevista pessoal, 14 de janeiro de 2019).

Por sua vez, o professor José Evelio Gutiérrez Hernández ${ }^{21}$ salienta o caráter informal desta rede: "Yo pienso que nosotros tenemos una red que existe, que es real, pero que es un tanto informal, más bien por los contactos que hemos desarrollado entre geógrafos cubanos y brasileños” (entrevista pessoal, 16 de janeiro de 2019).

20 O professor Julio Iván González Piedra, que tem como linha de pesquisa o estudo da Hidrologia, nos concedeu a entrevista em sua sala na Faculdade de Geografia da Universidade de Havana, no dia 14 de janeiro de 2019.

21 O professor José Evelio Gutiérrez Hernadez nos recebeu na Faculdade de Geografia da Universidade de Havana no dia 16 de janeiro de 2019 e lá nos concedeu a entrevista. Sua linha de trabalho envolve a geografia física, hidrologia, bacias hidrográficas e a questão da água e cidade. 
Finalmente, a professora Iñiguez Rojas nega categoricamente a existência de redes acadêmicas entre Brasil e Cuba:

Não! Mas é claro que não! Muito provável, tenho quase certeza de que nem os geógrafos aqui em Cuba conhecem tudo o que os geógrafos cubanos têm feito no Brasil, porque têm geógrafos no Brasil em diferentes lugares, geógrafos que moram no Brasil há muito tempo e que a gente perdeu o contato, nem se sabe o quê, que estão fazendo (L.B. Iñiguez Rojas, entrevista pessoal, 22 de janeiro de 2019).

Diante dos fatos postos, grande parte dos professores consultados colocou em dúvida a possibilidade de haver a constituição de redes acadêmicas, pois os fluxos (Santos, 2012) e o sentido de conexidade (Dias, 2000) são descontínuos ao longo do tempo. Por isso, alguns preferem falar de redes informais, virtuais, incipientes ou efêmeras. Entre os vários fatores da descontinuidade, muito mais expressivo está a dependência de fomentos para o desenvolvimento contínuo das pesquisas. Também, de maneira geral, muito mais pelos professores cubanos foi destacado que o fator financeiro é um grande empecilho para a construção dessa rede.

Esta questão nos levou a perguntar se mais que redes acadêmicas formais, os pesquisadores não haviam construído círculos de afinidade. Pois, como demonstraram muitas falas, embora sejam ligações científicas, elas são também de amizade e afetividade.

Vicent Berdoulay, em seu livro A Escola Francesa de Geografia: Uma Abordagem Contextual (2017), fala de círculos de afinidade para se referir "aos geógrafos que estavam ligados entre si, não somente pelos contatos diretos que mantinham como também por meio de personalidades que frequentavam ou de correntes ideológicas às quais gostavam de se referir" (Berdoulay, 2017:135). Para este autor, os fatores de formação dos círculos de afinidade são: as mudanças na visão de mundo; divergências ideológicas e a organização do trabalho científico. Em relação ao fator organização do trabalho científico, ele salienta que "o grau de organização coletiva do trabalho científico variava muito, de acordo com o grupo de pesquisadores considerado. Malgrado as impressões iniciais de que se poderia ter, nenhum geógrafo trabalhava inteiramente isolado" (Berdoulay, 2017:142).

Duas questões permitem falar da formação de círculos de afinidades entre geógrafos e geógrafas do Brasil e de Cuba. Em primeiro lugar, uma comunidade ideológica e o interesse por organizar o trabalho científico de forma coletiva em torno de temáticas como: geografia física, da saúde, urbana e agrária. Em outras palavras, uma leitura crítica das transformações territoriais recentes para além das formações disciplinares.

Em segundo lugar, em nossa pesquisa notamos que os círculos têm se caracterizado pelas relações construídas a partir de uma visão de mundo compartilhada, pelas experiências e afetos que se vão vivenciando a partir dos encontros de cooperação e que, muitas vezes, envolvem especialistas em outras áreas disciplinares. Isso fica claro na fala de nossos depoentes. Por exemplo, Iñiguez Rojas diz: "Eu trabalhei com uma socióloga e alguns estudantes da UFRJ” (entrevista pessoal, 22 de janeiro de 2019). Já Spósito afirma: "Veio também Pablo San Marful, que é um sobrinho do Eduardo, 
AdÉlIA ApARECIDA de SOUZA HaRACENKo

que é arquiteto, mas que estuda a cidade como forma, pelo menos estudava naquele momento. E ele ficou com a gente aqui, durante três meses" (entrevista pessoal, 19 de outubro de 2018). Por sua vez Fernandes salienta:

(...) nos estudos de geografia agrária, eu falava para eles: "Gente! Tem uma questão agrária aqui.” Eu fui para campo, tem uma questão agrária socialista. E eles: “Não, Bernardo, a questão agrária é só capitalista." E eu acabei convencendo eles de que nós temos uma questão agrária também no socialismo. Eu estou querendo trabalhar com isso agora, tenho debatido com vários colegas de Cuba que começaram a pensar sobre esse tema da questão agrária socialista: um professor de sociologia e economia política da Universidade de Havana, Juan Valdés, ele é o meu principal interlocutor hoje na construção desse conceito. Estivemos juntos no México na Argentina e ele falou: "Bernardo, nunca tinha pensado nisso.” E essa questão é uma questão importante (B.M. Fernandes, entrevista pessoal, 29 de outubro de 2018).

A proposta do professor Fernandes permitiu analisar o território cubano por outro ponto de vista. Ou seja, a criticidade emerge a partir do momento que se passa a refletir sobre o conceito de questão agrária posta também em um sistema socialista. Uma questão que merece ser salientada é que tanto a formação dos círculos de afinidades, entre os geógrafos e geógrafas de Rio Claro, Presidente Prudente e Ceará, quanto o processo de circulação de ideias entre Brasil e Cuba foram promovidos por Mateo Rodríguez, considerado como a figura central mediadora das relações. Neste sentido da Silva afirma:

Então, eu acho assim que o grande mentor de tudo isso é o Mateo, e nós temos uma relação de amizade e de pesquisa e trabalho muito grande. Mas para mim ele é meu mestre, meu professor. (...) Nós precisamos de pessoas que nos acompanhem ao campo, que nos dê novas ideias e que sejam humildes, como é o caso do Mateo (E.V. da Silva, entrevista pessoal, 22 a 29 de julho de 2018).

Em São Paulo, Presidente Prudente, a professora Maria Encarnação Beltrão Sposito ${ }^{22}$ comenta:

(...) para que isso ocorresse, uma figura superimportante é o professor Mateo, que não apenas veio inúmeras vezes para o Brasil e que começou com uma atuação na minha unidade. Muito consciente, muito sério, muito comprometido com a realização da pesquisa com o Brasil. O professor Mateo fez relações acadêmicas com Presidente Prudente, com Rio Claro, com o Ceará, enfim, (...) sempre eu senti no professor Mateo a grande figura que valorizou esse conjunto de parcerias (M.E.B. Sposito, entrevista pessoal, 3 de janeiro de 2019).

Por seu lado, a professora cubana Maria Gloria Fabregat Rodríguez ${ }^{23}$ reforça esta visão oferecida pelos professores brasileiros:

22 Entrevista realizada com a professora Maria Encarnação Beltrão Sposito no dia 3 de janeiro de 2019. Dedica-se aos estudos de geografia urbana, com ênfase aos temas: produção do espaço urbano e cidades médias.

23 A professora cubana Maria Gloria Fabregat Rodríguez nos concedeu a entrevista no dia 19 de outubro de 2018, nas dependências do departamento de geografia da UNESP de Presidente Prudente quando, na ocasião, ali desenvolvia seu pós-doutoramento. Dedica-se a estudos de questões ambientais e da saúde. 


\begin{abstract}
Hemos tenido la suerte también de tener a geógrafos buenos y el exponente máximo, para mí, es Mateo, que ha sido una persona que tiene más de diez libros escritos. Entonces va a dejar una enseñanza a la geografía de Cuba y un poco más allá, desde la teoría a la metodología, pasando por el trabajo práctico o la implementación real de la geografía. Entonces, esa fortaleza de la geografía cubana creo que (...), a través de Mateo, comenzó a llegar a Brasil. (...) Mateo es un geógrafo de alta dimensión, con una formación muy completa y, además, él adora Brasil (M.G. Fabregat Rodríguez, entrevista pessoal, 19 de outubro de 2018).
\end{abstract}

Os apoios financeiros permitiram que as pessoas que conformaram estes círculos de afinidades acentuassem seus encontros em determinados momentos de maior intensidade de trabalho, todavia, o que notamos é que esses vínculos não têm deixado de existir.

\title{
Notas a considerar
}

Neste artigo buscamos identificar os vínculos entre a geografia brasileira e a geografia cubana, visando contribuir para a circulação do conhecimento geográfico feito na América Latina. Na nossa pesquisa, a história oral foi uma importante ferramenta metodológica na medida em que nos permitiu reconhecer os contatos e formas de cooperação entre os geógrafos e geógrafas dos dois países.

No Congresso da União Geográfica Internacional celebrado no Rio de Janeiro em 1956, marco de recorte temporal desta pesquisa, houve apenas contatos: as relações só vão se efetivar a partir dos anos de 1980. Entretanto, a partir dos anos 1990 com o aporte financeiro dos governos mais progressistas, esses vínculos puderam ser intensificados, tendo no projeto CAPES/MES nos anos de 2000 um importante apoio ao desenvolvimento das pesquisas em colaboração. Com o desenvolvimento dos mapas de intensidade de colaboração acadêmica entre Cuba e Brasil por instituição e por estado, pudemos perceber que uma grande quantidade de instituições brasileiras teve e tem algum tipo de relação com a geografia cubana, sendo as Universidades de Presidente Prudente, Rio Claro e Ceará as que têm mais contatos com a geografia da Universidade de Havana.

Chamamos a atenção ao fato de que para a maioria dos geógrafos e geógrafas entrevistados, não há uma rede formal constituída de pesquisa. Esse fato está muito ligado ao fomento para o desenvolvimento dos projetos, ou seja, as pesquisas permanecem enquanto há recursos financeiros. A ausência delas tem limitado a construção de uma rede formalizada. Todavia, as relações constituídas ao longo do tempo permitiram o desenvolvimento de círculos de afinidades, pelos contatos diretos, por uma visão de mundo e os objetos de pesquisas em comum. É, portanto, nesse processo que se dá a produção do conhecimento, as viagens das teorias e a circulação de ideias geográficas. Neste sentido:

Estamos perante um exemplo de circulação dos saberes, de tradução e troca cultural que envolve não somente o pensamento geográfico, mas também a ligação entre geografia, crítica social, movimentos políticos progressistas e defesa da liberdade científica e civil (Ferretti, 2015:15). 
AdÉlIA ApARECIDA de SOUZA HaRACENKo

Por fim, ousamos propor que este estudo possa resultar em uma contribuição para a reflexão e ampliação do debate que direcione rumo a uma geografia latino-americana fortalecida em seus vínculos e para a construção de um pensamento dos geógrafos e geógrafas latinos. Mais do que nunca, em sua história de saber científico, a geografia, a partir dos primórdios do ano de 2020 terá que se reinventar, pois o mundo pós pandemia exigirá novos desafios. O diálogo entre os cientistas latinos terá que ser fortalecido. Que o futuro nos conduza a uma realidade latino-americana compreendida por uma geografia também latino-americana.

Desta maneira, é no trilhar do caminho da práxis que as descobertas acontecem... e o aprendizado se concretiza...

Agradeço aos geógrafos e geógrafas brasileiros e cubanos envolvidos nessa investigação. Em especial, à professora Perla Brígida Zusman que ao aceitar a supervisão da pesquisa, prontamente, também aceitou o desafio de trilhar esse caminho junto comigo. 


\section{Bibliografia}

» Berdoulay, V. (2017). A escola francesa de geografia: uma abordagem contextual. São Paulo: Perspectiva.

»Capel, H. (2012). Filosofía y ciencia en la geografía contemporánea: una introducción a la geografía. Barcelona: Ediciones del Serbal.

»Da Silva, J.B. (2012). França e a escola brasileira de geografia: verso e reverso. Fortaleza: Edições UFC.

» De Campos, R.R. (2011). Breve histórico do pensamento geográfico brasileiro nos séculos XIX e XX. Jundiaí: Paco Editorial.

» De Queiroz, M.I.P. (1991). Variações sobre a técnica de gravador no registro da informação viva. São Paulo: T.A. Queiroz Editor.

» Dias, L.C. (2000). Redes, emergência e organização. Em I.E., de Castro, P.C. da C. Gomes, R.L. Corrêa (Org.), Geografia: Conceitos e temas (2da ed.) (pp. 141-162). Rio de Janeiro: Bertrand Brasil.

» Evangelista, H. de A. (2014). Aspectos históricos da geografia brasileira. Rio de Janeiro: Letra Capital.

»Fausto, B. (1997). História do Brasil (5 ed.). São Paulo: Edusp.

» Ferretti, F. (2015, dezembro 17). A recepção de Elisée Reclus na Itália e na América do Sul por Luigi e Luce Fabbri (1903-2000). Troca cultural e circulação do saber geográfico. Terra Brasilis. Disponível em: https://journals.openedition.org/ terrabrasilis $/ 1413$

» Gonçalves, C.W.P. (1982). A geografia está em crise. Viva a geografia. Em R. Moreira (Org.), Geografia: teoria e crítica. O saber posto em questão (pp. 93-113). Petrópolis: Vozes.

» Mateo Rodríguez, J. M. (2015). Teoría y metodología de la Geografía. La Habana: Editorial Universitaria Félix Varela.

» Mateo Rodríguez, J.M. (2014). Diálogo sobre a geografia cubana. Entrevista realizada por Silva, P. F. J. da Silva. Geoatos, 1(14), 93-98. Recuperado de: http:// revista.fct.unesp.br/index.php/geografiaematos/article/view/2639

» Meihy, J. C. S. B. (1996). Manual de história oral. São Paulo: Edições Loyola.

» Moreira, R. (2000). Assim se passaram dez anos (A renovação da geografia no Brasil no período 1978-1988). GEOgraphia, 2(3), 27-49. Recuperado de: https:// periodicos.uff.br/geographia/article/view/13373

» Moreira, R. (2011). Pensar e ser em geografia: ensaios de história, epistemologia e ontologia do espaço geográfico. São Paulo: Contexto.

» Moreira, R. (2014). O discurso do avesso: para a crítica da geografia que se ensina. São Paulo: Contexto.

» Moura, R., de Oliveira, D., Lisboa, H. dos S., Fontoura, L.M. e Geraldi, J. (2008). Geografia Crítica: legado histórico ou abordagem recorrente? Biblio 3W, Revista Bibliográfica de Geografía y Ciencias Sociales, 13(786). Recuperado de: http:// www.ub.es/geocrit/b3w-786.htm 
»Programa CAPES/MES-Cuba. Coordenação de Aperfeiçoamento de Pessoal de Nível Superior e Ministério da Edizacao Superior (CAPES/MES-Cuba) (2007). Edital, 11. Recuperado de: http://capes.gov.br/bolsas-e-auxilios-internacionais/ pais/202-cuba/9584-mes-projetos

"Said, E.W. (2008). Teoría ambulante. Em El mundo, el texto y el crítico (pp. 303330). Espanha: Debolsillo. Tradução de Ricardo García Pérez. Recuperado de: https://kupdf.net/download/said-edward-teor-iacute-a-ambulante-el-mundo-eltexto-y-el-cr-iacute-tico_5afb5448e2b6f5bc481d29e6. Acesso em 02 de março de 2020.

»Santos, M. (1995). Nuevas concepciones de la Geografía. Conferencia magistral, $\checkmark$ Encuentro de Geógrafos de América Latina. Habana, Cuba. Recuperado de: https://www.youtube.com/watch?v=6g8Fqu_Xitg

"Santos, M. (2012). Metamorfoses do espaço habitado: fundamentos teóricos e metodológicos da geografia (6 ed.). São Paulo: EDUSP.

"Scarim, P.C. (2000). Coetâneos da crítica: contribuição ao estudo do movimento de renovação da geografia brasileira. Tese de doutorado em Geografia, Universidade de São Paulo.

》 UGI (Union Géographique Internationale) (1959). Comptes Rendus du XVIIlème Congrès Internacional de Géographie. Tome Premier. Actes du Congrès. Rio de Janeiro: UGI, Comité National du Brésil.

» UGI (Union Géographique Internationale) (1959). Comptes Rendus du XVIIlème Congrès Internacional de Géographie. Tome Quatrième. Travaux des Sections. Rio de Janeiro: UGI, Comité National du Brésil.

»Valverde, O. (1984). Evolução da geografia brasileira no após guerra. Carta aberta de Orlando a Orlando. Boletim Paulista de Geografia, 60, 5-20. Recuperado de: https://www.agb.org.br/publicacoes/index.php/boletim-paulista/issue/view/86

Adélia Aparecida de Souza Haracenko / haracenko@gmail.com Licenciada, Doutora em Geografia pela Universidade de São Paulo. Professora Associada da Universidade Estadual de Maringá (UEM), Brasil. Professora do Departamento de Geografia desta Universidade, com investigações voltadas à Geografia Agrária e História do Pensamento Geográfico. Pós-doutorado (2018-2019) pela Universidade de Buenos Aires, com supervisão da professora Perla Brígida Zusman. 